\title{
On the formation, ventilation, and erosion of mode waters in the North Atlantic and Southern Oceans
}

\author{
D. S. Trossman, ${ }^{1,2}$ L. Thompson, ${ }^{2}$ S. Mecking, ${ }^{2,3}$ and M. J. Warner ${ }^{2}$ \\ Received 26 March 2012; revised 24 July 2012; accepted 7 August 2012; published 21 September 2012.
}

[1] The mean residence times, subduction rates, and formation rates of Subtropical Mode Water (STMW) and Subpolar Mode Water (SPMW) in the North Atlantic and Subantarctic Mode Water (SAMW) in the Southern Ocean are estimated by combining a model and observations of chlorofluorocarbon-11 (CFC-11) via Bayesian Model Averaging (BMA), a statistical technique that weights model estimates according to how close they agree with observations. Subduction rates are estimated in two different ways to investigate the non-advective contribution to thermocline ventilation, which in turn are compared to formation rate estimates. One subduction rate estimate is based on entrainment/detrainment velocities and the other subduction rate estimate allows ventilation to be both an advective and diffusive process instead of a purely advective one by using transit-time distributions (TTDs). It is found that the subduction of all three mode waters is mostly an advective process, but up to about one-third of STMW subduction likely owes to non-advective processes. Also, while the formation of STMW is mostly due to subduction, the formation of SPMW is mostly due to other processes. About half of the formation of SAMW is due to subduction and half is due to other processes. A combination of air-sea flux, acting on relatively short timescales, and turbulent mixing, acting on a wide range of timescales, is likely the dominant SPMW erosion mechanism. Air-sea flux is likely responsible for most STMW erosion, and turbulent mixing is likely responsible for most SAMW erosion.

Citation: Trossman, D. S., L. Thompson, S. Mecking, and M. J. Warner (2012), On the formation, ventilation, and erosion of mode waters in the North Atlantic and Southern Oceans, J. Geophys. Res., 117, C09026, doi:10.1029/2012JC008090.

\section{Introduction}

[2] Mode waters are the manifestation of air-sea interaction; they are typically formed during the wintertime in regions of locally deep mixed layers. They then subduct and ventilate the thermocline [McCartney, 1977, 1982]. Mode waters are characterized by minima in large-scale potential vorticity [McCartney and Talley, 1982] in the vertical, making them homogeneous water masses within the thermocline. Their physical characteristics [Worthington, 1959; McCartney, 1982], how they form [Speer and Tziperman, 1992], how they subduct [Luyten et al., 1983; Musgrave, 1990], and their interannual variability in volume [Kwon and Riser, 2004] and rate of ventilation [Liu and Huang, 2012] have been studied, but many questions remain about the formation

\footnotetext{
${ }^{1}$ Department of Earth and Environmental Sciences, University of Michigan, Ann Arbor, Michigan, USA.

${ }^{2}$ School of Oceanography, University of Washington, Seattle, Washington, USA.

${ }^{3}$ Applied Physics Laboratory, University of Washington, Seattle, Washington, USA.

Corresponding author: D. S. Trossman, Department of Earth and Environmental Sciences, University of Michigan, 2534 C. C. Little Science Bldg., 1100 N. University Ave., Ann Arbor, MI 48109, USA. (dtross@umich.edu)

(C2012. American Geophysical Union. All Rights Reserved. 0148-0227/12/2012JC008090
}

and destruction of mode waters. This manuscript examines 1) the dominant mechanisms responsible for mode water erosion, 2) the timescales of mode water erosion, 3) the differences between the rate of mode water subduction due to advection and the rate of total mode water subduction, and 4) the differences between the rate of mode water formation due to subduction and the rate of total mode water formation. We restrict our analysis here to the North Atlantic and Southern Oceans.

[3] The North Atlantic's subtropical gyre has been extensively studied and provides the motivation for the ventilation theory developed by Luyten et al. [1983]. The theory defines subduction as occurring when water leaves the mixed-layer and enters the permanent thermocline. In the theory, the transfer occurs where the fluid parcels are downwelled and move equatorward within the large scale circulation. After that, the water primarily follows - and is advected and diffused around - the gyre. Turbulent erosion of the peripheries of the mode water occurs after subduction. The mode water erodes further along its path until the next time its isopycnals outcrop when mode waters can also erode via entrainment into the mixed layer and air-sea fluxes. One of the primary goals of this study is to investigate the relative roles of mode water erosion via entrainment back into the mixed layer, turbulent mixing below the mixed layer, and air-sea fluxes.

[4] Previous studies have shown that there is a substantial amount of inter-annual variability in the ventilation rates of 
Table 1. Tracer Data Collected in the Listed Years (Before 2006) Along Each of the Cross-Sections of Interest

\begin{tabular}{lccc}
\hline $\begin{array}{l}\text { WOCE } \\
\text { Section }\end{array}$ & Latitude(s) & Longitude(s) & CFC-11 \\
\hline A16(N) & $34^{\circ} \mathrm{N}$ to $63^{\circ} \mathrm{N}$ & $20^{\circ} \mathrm{W}$ & $1988,1993,1998,2003$ \\
A05 & $24.5^{\circ} \mathrm{N}$ & $79^{\circ} \mathrm{W}$ to $14^{\circ} \mathrm{W}$ & $1992,1998,2004$ \\
A20 & $20^{\circ} \mathrm{N}$ to $41^{\circ} \mathrm{N}$ & $53.5^{\circ} \mathrm{W}$ & 1997 \\
SR03 & $67^{\circ} \mathrm{S}$ to $43^{\circ} \mathrm{S}$ & $135^{\circ} \mathrm{E}$ to $147^{\circ} \mathrm{E}$ & 1995,2001 \\
I09(S) & $63^{\circ} \mathrm{S}$ to $35^{\circ} \mathrm{S}$ & $115^{\circ} \mathrm{E}$ & 1995 \\
P16 & $71^{\circ} \mathrm{S}$ to $16^{\circ} \mathrm{S}$ & $150^{\circ} \mathrm{W}$ & 2005 \\
A21 & $63^{\circ} \mathrm{S}$ to $55^{\circ} \mathrm{S}$ & $68^{\circ} \mathrm{W}$ to $63^{\circ} \mathrm{W}$ & 1990 \\
\hline
\end{tabular}

North Atlantic mode waters. Trossman et al. [2009] have used satellite and profiler observations with an advective parcel tracking model to estimate the subduction rate of Subtropical Mode Water (STMW), also known as Eighteen Degree Water (EDW), to be 3-8 Sv, consistent with previous estimates [Kwon, 2003]. Hall et al. [2007] made use of chlorofluorocarbon (CFC) observations and a one-way mass flux that accounts for mixing to estimate the subduction rate of STMW to be 6 Sv. McCartney and Talley [1982] hypothesized that, after being subjected to deep convection in the wintertime, the density of Subpolar Mode Water (SPMW) increases along the path of the subpolar gyre due to heat loss. Brambilla et al. [2008] inferred that most of the transformation of waters into SPMW density classes is due to diapycnal fluxes and that SPMW subduction is the result of the entrainment of lighter waters into the deep overflows of the subpolar gyre. The formation rate of SPMW is estimated to be 7.5-20.5 Sv [Brambilla et al., 2008], but how much of this ventilates the interior is unclear.

[5] Most of the Subantarctic Mode Water (SAMW) is found between $100^{\circ} \mathrm{E}$ to $60^{\circ} \mathrm{W}$ and is subducted in the Indian and Pacific Ocean sectors [Sallée et al., 2010]. Some SAMW is formed by deep mixing on the northern side of the ACC, where water (north of $50^{\circ} \mathrm{S}$ ) is downwelled [Sallée et al., 2006]. Downes et al. [2011] suggested, using model simulations, that Upper Circumpolar Deep Water (UCDW) and Antarctic Intermediate Water (AAIW) may be converted into SAMW via surface buoyancy fluxes and that cabbeling and thermobaricity may play crucial roles in water mass transformation in the Southern Ocean. Hartin et al. [2011] have estimated that the formation rate of SAMW is $11.7 \pm$ $2.2 \mathrm{~Sv}$ in the South Pacific Ocean based on transient tracer inventories. Sloyan and Rintoul [2001] have estimated the formation rate of SAMW to be about $6.5-8.5 \mathrm{~Sv}$ in the Indian Sector of the Southern Ocean based on an inverse model and observations, and Sloyan and Rintoul [2001] estimated the formation rate of SAMW to be about 23.6 Sv over the entire Southern Ocean.

[6] Liu and Huang [2012] suggest a trend in ventilation rates over the entire World Ocean using the Simple Ocean Data Assimilation data set [Carton et al., 2000], but were unable to ascertain a mechanism for this trend or whether this trend was significant. Here, we calculate the time series of subduction rates (and their uncertainties) for SAMW (Southern Ocean), STMW (North Atlantic Ocean), and SPMW (North Atlantic Ocean) using hydrographic sections that cross the Southern, Subtropical North Atlantic, and Subpolar North Atlantic Oceans, respectively, with a statistical technique called Bayesian model averaging (BMA) [Hoeting et al., 1999]. BMA incorporates observations by treating model runs as random variables themselves, each with an associated posterior probability (roughly interpreted to be the degree of our belief that a model simulates the observations better than other models) that we use to weight the outputs to come up with a final estimate. The observations we use here are CFC-11 concentrations because CFCs are inert, anthropogenic, biologically inactive tracers that provide information about water that has been in contact with the atmosphere within the last 75 years. CFC-11 concentrations in the ocean have a greater dynamic range than CFC-12 concentrations due to its higher solubility and similar detection limit. Hence, we choose CFC-11 to assess model simulation performance. The World Ocean Circulation Experiment (WOCE) Hydrographic Program and Climate Variability and Predictability (CLIVAR) \& Carbon Repeat Hydrography Program observations (Table 1) are utilized along with outputs from several isopycnal coordinate model runs. The output from these model runs are averaged according to weights generated by using BMA, taking all measurement and mapping error into account.

[7] In order to evaluate the contribution of turbulent mixing to the erosion of mode waters, the contribution of diffusion to thermocline ventilation, and the timescales over which mode waters erode, we estimate a transit-time distribution, or TTD [Holzer and Hall, 2000], at each point according to the boundary impulse response (BIR) estimation method evaluated by Haine et al. [2008]. A TTD is a Green's function solution to the three-dimensional advection-diffusion equation that quantifies the fraction of mass that gets from a boundary (e.g., the surface of the ocean) to some other location (e.g., the interior of the ocean) from the time a tracer enters the ocean at the boundary to some other time. This time interval is referred to as an 'age'. A purely advective water parcel would have a delta spike for a TTD, so the halfvariance of the TTD essentially is a measure of mixing extent between waters of different ages [Waugh et al., 2003]. A TTD can be related to the mean residence time of a water mass, the volume of water mass transported into the ocean interior for each age class [Hall et al., 2007], and the fraction of water mass that is eroded for each age class [Primeau and Holzer, 2006]. We calculate TTD-based subduction rate estimates [Hall et al., 2007], which take advection and diffusion into account by relating the TTD and its derivative to a volume transport. For comparison, we also calculate entrainment/detrainment velocity-based subduction rate estimates [Ladd and Thompson, 2001], which assumes that diffusion is negligible once water has been subducted. This is accomplished offline by integrating the difference between detrainment and entrainment rates over the area where a mode water's isopycnals outcrop.

[8] The main topics of this paper are arranged as follows: We discuss the observations (section 2.1) and describe an ensemble of model runs (section 2.1.1) used in this study. We review how a TTD is related to mass flux in section 2.2. In section 2.3, we discuss how to apply the BMA method for our application. All of the model simulations are weighted to find final estimates of SAMW, STMW, and SPMW mean residence times, subduction rates, formation rates, and relative contributions of turbulent mixing and 


\section{North Atlantic Ocean WOCE sections}

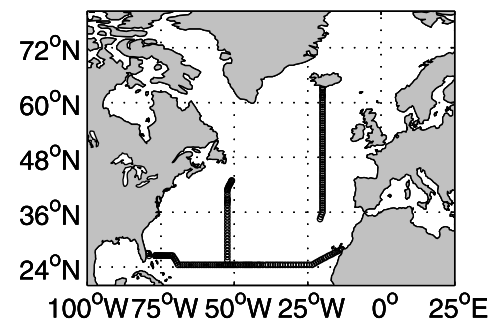

\section{Southern Ocean WOCE sections}

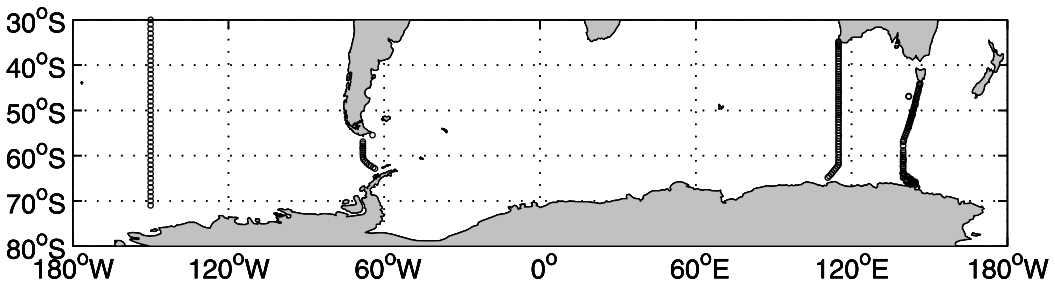

Figure 1. Locations of bottle data measurements used in this study taken along WOCE transects (open black circles), listed in Table 1.

entrainment to erosion. Uncertainties on these estimates are quantified.

\section{Methods}

[9] Our approach to estimating the mean residence times, subduction rates, formation rates, and relative contribution of two types of erosion requires information from both observations and a numerical model. In the following subsections, we describe the information we use from observations and the model simulations to arrive at our estimates.

\subsection{Data}

[10] For observational constraints on our estimates, we use CFC-11 concentrations, collected in different years, along repeat hydrographic sections (Table 1). We choose these sections because they intersect most of the regions where the three mode waters of interest in this study are thickest in our model (see section 3.3.2). These sections are as follows (Figure 1): The SR03 section (from $67^{\circ} \mathrm{S}$ to $44^{\circ} \mathrm{S}$, between $135^{\circ} \mathrm{E}$ and $147^{\circ} \mathrm{E}$ ) is a meridional transect that extends from Tasmania to Adélie Land of Antarctica. The I09S (I09 hereafter) section (from approximately $32^{\circ} \mathrm{S}$ to $63^{\circ} \mathrm{S}$ between $105^{\circ} \mathrm{E}$ and $110^{\circ} \mathrm{E}$ ) is a meridional transect that crosses the Indian and Southern Oceans west of Australia. The P16(S) section (from $71^{\circ} \mathrm{S}$ to $16^{\circ} \mathrm{S}$ along $150^{\circ} \mathrm{W}$ ) is a meridional transect that crosses the Pacific Sector of the Southern Ocean. The A21 section (from $63^{\circ} \mathrm{S}$ to $55^{\circ} \mathrm{S}$ between $63^{\circ} \mathrm{W}$ and $68^{\circ} \mathrm{W}$ ) is a meridional transect that crosses the Drake Passage. The A16 section (from $63^{\circ} \mathrm{N}$ to approximately $34^{\circ} \mathrm{N}$ along $20^{\circ} \mathrm{W}$ and southward to approximately $55^{\circ} \mathrm{S}$ between $20^{\circ}$ and $36^{\circ} \mathrm{W}$ ) is a meridional transect that crosses the MidAtlantic Ridge near the equator, such that it is in the eastern basin in the North Atlantic and the western basin in the South Atlantic. The A05 section is a zonal transect that follows $24^{\circ} \mathrm{N}$ from about $20^{\circ} \mathrm{W}$ to about $79^{\circ} \mathrm{W}$ in the North Atlantic. The A20 section (from $21^{\circ} \mathrm{N}$ to $41^{\circ} \mathrm{N}$ along $53.5^{\circ} \mathrm{W}$ ) is a meridional transect from Brazil to Newfoundland. The years in which the CFC-11 data were taken for each section are listed in Table 1.

\subsubsection{Model Runs}

[11] The numerical model we use is called Offtrac, an offline advection diffusion code in isopycnal coordinates [Deutsch et al., 2011]. Offtrac uses mass flux fields taken from runs of the Hallberg Isopycnal Model (HIM) [Hallberg, 1995]. HIM is a 49-layer, isopycnal coordinate, nominally $1^{\circ}$ longitudinal model on a tripolar grid that has been forced by the repeat annual cycle Coordinate Ocean Reference Experiment (CORE) data set [Large and Yeager, 2004]. CORE uses 6 hourly fields to force the model, and the output of HIM is monthly. In HIM, diapycnal diffusion is according to the scheme of Hallberg [2000] and along-isopycnal thickness diffusion is $600 \mathrm{~m}^{2} \mathrm{~s}^{-1}$. The latter diffusivity represents the along-isopycnal mixing by mesoscale eddies. An offline isopycnal coordinate model is ideal for this study because we can vary the background along-isopycnal diffusivity of passive tracers without changing the circulation. Also, once HIM generates two different (hindcast and climatological) circulation fields, we can vary the circulation in Offtrac by using the hindcast or climatological fields while keeping the along-isopycnal diffusivity of passive tracers constant. The diffusivity of passive tracers along isopycnals can be varied at will in this isopycnal coordinate model without violating overall constraints on mass conservation.

[12] Monthly climatological three-dimensional mass flux fields (along and across isopycnal surfaces) were constructed from the last 10 years of a 250-year spin-up of HIM, using the CORE fields as input. Hindcast mass flux fields were also calculated in HIM forced by CORE-based precipitation, radiation, relative humidity, sea level pressure, temperature at 10 meters above sea level, and wind velocity fields at 10 meters above sea level from January 1958 to December 2006 [Large and Yeager, 2004] as input for HIM. For runs in which we allow the mass flux fields to vary from 
Table 2. The Observed Potential Density Ranges, $\sigma_{\theta}=$ $\rho_{\theta}-1000\left(\mathrm{~kg} \mathrm{~m}^{-3}\right)$, of Subantarctic Mode Water (SAMW), Subtropical Mode Water (STMW), Subpolar Mode Water (SPMW), and Labrador Seawater (LSW) From Previous Studies

\begin{tabular}{lcc}
\hline Water Mass & $\sigma_{\theta}$ & Reference \\
\hline SAMW & $26.5-27.05$ & Sallée et al. $[2006]$ \\
STMW & $26.0-26.6$ & LeBel et al. [2008] \\
SPMW & $27.2-27.5$ & McCartney and Talley [1982]; \\
& & Brambilla et al. $[2008]$ \\
LSW & $27.4-27.7$ & Johnson et al. $[2005]$ \\
\hline
\end{tabular}

year to year, the twelve monthlong climatological fields are first repeated each year for 29 years from 1930, just before the year that CFCs were introduced into the atmosphere, to 1958. In the model calendar year, 1959, we begin using the HIM-derived monthly hindcast fields of variable wind stress, density layer thickness, temperature, salinity, zonal and meridional transport, and diapycnal transport fields. The hindcast fields are then repeated every 47 years (January 1959 to December 2005). For a simulation in which the mass flux fields are the same from year to year, the climatological fields are used. Gas exchange parameterization follows the Ocean Carbon-cycle Model Intercomparison Project (OCMIP-2) protocol [Doney et al., 2004]. Thirty nested iterations of this gas exchange step are completed at each monthly time step in the Offtrac model because mixed layer CFCs come into equilibrium with the atmosphere on timescales shorter than one month.

[13] We perform six 76-yearlong (1930 through 2005) simulations of CFC-11: the first three with climatological circulation fields, each with different along-isopycnal diffusivities, $5 \times 10^{2}, 1 \times 10^{3}$, and $1 \times 10^{4} \mathrm{~m}^{2} \mathrm{~s}^{-1}$, and then we perform three simulations with variable (hindcast) circulation fields, each with one of the three different diffusivities given above. The range of diffusivities was chosen based on the model simulations done by Mecking et al. [2004], Abernathey et al. [2010], and Shuckburgh et al. [2011].

[14] In addition to the six different 76 yearlong simulations of CFC-11, TTDs were calculated using Offtrac by introducing initial boundary impulses at mostly five year intervals (years $t_{0}=1959,1964,1969, \ldots, 2004$, and 2005) using repeated hindcast fields and then averaging the boundary impulse responses (BIR TTD, hereafter) together [Haine et al., 2008]. The total length of each BIR TTD simulation was 200 years. Each BIR TTD is estimated by letting the surface of the ocean be $1 / \Delta \tau$ for an entire year, where $\Delta \tau$ is taken to be one year, and keeping track of the values of this tracer. We perform three simulations using the hindcast fields, each using different along-isopycnal diffusivities, $\kappa_{H}$, for each starting time of the TTD. In addition, we perform simulations with the climatological circulation fields also using the three different $\kappa_{H}$. This gives $3 \times 11$ hindcast and 3 climatological (i.e., 36) model simulations of the TTD. For each of the 36 members in our ensemble of model simulations, we compute the TTD from $t_{0}$ to $t_{0}+200$ years. Use of a single model BIR TTD estimate for each five year interval is an approximation to the model TTD starting at time $t_{0}$ because the hindcast fields are unsteady. Therefore, we average all of the BIR TTDs over the unsteady circulation period (47 years) to get an estimate of the TTD for each model configuration and time. The computation time and storage space required to introduce initial boundary impulses every year, which can be averaged over the unsteady circulation period to yield a better estimate of the model TTD, precludes us from taking this approach.

\subsubsection{Identification of Water Masses}

[15] The large scale potential vorticity in the $k$ th layer, $P V_{k}$, is used to identify the location of SAMW, STMW, and SPMW in the model [Ladd and Thompson, 2001],

$$
P V_{k}=\frac{f}{\rho_{k}} \frac{\frac{1}{2}\left(\rho_{k+1}+\rho_{k}\right)-\frac{1}{2}\left(\rho_{k}+\rho_{k-1}\right)}{h_{k}}
$$

where $\rho_{k}$ is the potential density at the $k$ th isopycnal layer, $f$ is the Coriolis parameter, and $h_{k}$ is the thickness of the $k$ th isopycnal layer in the model. (To calculate the derivatives, we ignore the isopycnal layers that are less than a centimeter thick in the model.) We find the depths at which the magnitude of large-scale potential vorticity, $|P V|$, is near its minimum in the vertical. That is, we look for depths at which $\partial|P V| / \partial|z|=0$ (|z| increases with depth) and $\partial^{2}|P V| / \partial|z|^{2}>0$ at each horizontal grid point in the domains of the North Atlantic and Southern Oceans. We identify SAMW, STMW, and SPMW as the waters where this condition is satisfied with $|P V|<1 \times 10^{-3} \mathrm{~m}^{-1} \mathrm{~s}^{-1}$ within a range of densities. We find mode waters with these two conditions because there are waters outside of a mode water's density range where the minimum in potential vorticity does not identify a mode water mass, and there are waters within a mode water's density range where there are water masses that are not mode waters. The range of densities used for each mode water mass was found by searching for the density layers where the potential vorticity criterion is satisfied over at least fifty meters of the upper 1000 meters of the water column over their respective ocean basins.

[16] The observed potential densities of SAMW, STMW in the North Atlantic Ocean, SPMW in the North Atlantic Ocean, and Labrador Seawater (LSW) are listed in Table 2. LSW is another nearly homogeneous water mass in the North Atlantic below the thermocline that also has a local vertical minimum in large-scale potential vorticity. LSW has a salinity minimum [Read, 2001] which we will use to distinguish it from SPMW. We limit identification of the mode waters to the longitudes and latitudes listed in Table 3 with the additional criterion for SPMW that the depths at which we find SPMW are also characterized by a salinity maximum (i.e., $\partial S / \partial|z|=0$ and $\partial^{2} S / \partial|z|^{2}<0$ ). The range of potential densities and potential vorticities for each mode water mass is listed in Table 3 . The potential density ranges listed in Tables 2 and 3 are slightly different due to differing definitions of the mode water from the studies cited in Table 2 and biases in the HIM fields. SAMW is found in the South Pacific and southeastern Indian Oceans, STMW southeast of the Gulf Stream, and SPMW over the southwest and southeast coasts of Iceland as well as within some of the rest of the Subpolar North Atlantic Ocean extending southwest to the Subtropical North Atlantic Ocean.

\subsection{Two Methods to Estimate Subduction Rates}

[17] Using only the locations where SAMW, STMW, or SPMW is present, we calculate the subduction rates of these 
Table 3. The Potential Vorticities (PV) $\left(\mathrm{m}^{-1} \mathrm{~s}^{-1}\right)$ and Potential Densities Minus 1000 (Minimum, $\sigma_{\theta \text {, min }}$, to Maximum, $\sigma_{\theta \text {,max }}$ That Vary Grid Point by Grid Point) ( $\mathrm{kg} \mathrm{m}^{-3}$ ) of Subantarctic Mode Water (SAMW), Subtropical Mode Water (STMW), and Subpolar Mode Water (SPMW) From the HIM Hindcast Circulation Fields

\begin{tabular}{lccccc}
\hline Water Mass & Circulation Fields & Longitudes & Latitudes & Mean $|P V|$ & $\sigma_{\theta, \min }-\sigma_{\theta, \max }$ \\
\hline SAMW & hindcast & $80^{\circ} \mathrm{E}-120^{\circ} \mathrm{W}$ & $60-25^{\circ} \mathrm{S}$ & $4.76 \times 10^{-4}$ & $26.6( \pm 0.0771)-26.9( \pm 0.0113)$ \\
STMW & hindcast & $80-5^{\circ} \mathrm{W}$ & $18-42^{\circ} \mathrm{N}$ & $4.27 \times 10^{-7}$ & $25.7( \pm 0.0506)-25.9( \pm 0.0377)$ \\
SPMW & hindcast & $60^{\circ} \mathrm{W}-20^{\circ} \mathrm{E}$ & $40-80^{\circ} \mathrm{N}$ & $3.42 \times 10^{-4}$ & $27.3( \pm 0.0390)-27.4( \pm 0.0552)$ \\
\hline
\end{tabular}

three water masses in two different ways: one using a TTD approach and one using the entrainment/detrainment velocities at the base of the mixed layer directly. We first describe the TTD approach. Primeau and Holzer [2006] and Hall et al. [2007] have shown that the rate of volume transported per unit time into a domain with volume, $V$, that will have resided at least $\tau=t-t_{0}$ before exiting equals

$$
\frac{\Phi_{+}(t, \tau)}{\rho}=V G\left(t, t_{0}\right)+V \int_{0}^{\tau} d t^{\prime} \frac{\partial}{\partial t} G\left(t, t-t^{\prime}\right) .
$$

Here, the TTD, $G(t, \cdot)$, is averaged over the grid points at which there is a water mass with density, $\rho$. We will be referring to $\Phi_{+}(t, \tau) / \rho$ as the "volume transport spectrum" hereafter. The residence time is $\tau$ for a water mass of density $\rho$ exiting $V$ that has resided in $V$ for $\tau$ amount of time before eroding (i.e., transforming by changing its density class). If the total mass of water that is eroded after residing in $V$ between $\tau$ and $\tau+\Delta \tau$ amount of time is $M_{e}$ and the total mass of water of density $\rho$ is $M_{m w}$, then the fraction of the water mass that is eroded is given by

$$
\left(\frac{M_{e}}{M_{w m}}\right)(t, \tau)=-\tau \frac{d \Phi_{+}(t, \tau)}{d \tau},
$$

and the rate of input of water that resides in $V$ for $\tau$ amount of time is $d \Phi_{+}(t, \tau) / d \tau$ [Primeau and Holzer, 2006]. We will be referring to $\left(M_{e} / M_{w m}\right)(t, \tau)$ as the "mass fraction erosion spectrum" hereafter. The residence time of a water mass is the ratio of the total mass to rate of input [Primeau and Holzer, 2006]. Both the volume transport spectrum, calculated via (2), and the mass fraction erosion spectrum, calculated via (3), are functions of the residence time, $\tau$.

[18] By using (2), we estimate the volume of water in density class, $\rho$, that subducts over an entire year, $t$, with $\int d \tau \Phi_{+}(t, \tau) / \rho$, which is the subduction rate in units of $\mathrm{m}^{3}$ for each year. By averaging over different boundary impulse initialization times spanning the time interval over which the hindcast fields are unsteady, we can estimate a model TTD which can in turn be related to a subduction rate of a particular density class of water. We use 36 model simulations (see section 2.1.1) to find the BIR TTD estimates that are averaged to approximate the TTD over 200 year periods at time intervals shifted by five years.

[19] Our estimate of the subduction rate from (2) is compared to an entrainment/detrainment velocity-based subduction rate estimate [Ladd and Thompson, 2001], which is calculated as

$$
V_{\text {ann }}=\iint_{\text {outcrop }} d A\left(w_{d e}-w_{e n}\right) .
$$

Here, $w_{d e}$ is the detrainment velocity (negative diapycnal velocity just below the base of the mixed layer) and $w_{e n}$ is the entrainment velocity (positive diapycnal velocity just below the mixed layer), each averaged over the time between when the winter mixed layer is deepest in one year and the time when the winter mixed layer is deepest in the following year. The integral in (4) is over the area of the ocean surface (outcrop) in which the density of the surface waters lies within the range of densities for a given mode water (Table 3). Evaluating (4) is accomplished offline using the monthly averaged output from HIM.

[20] In order to investigate the contribution of entrainment to mode water erosion, we compare the entrainment rates, estimated by setting $w_{d e}=0$ in (4), with estimates of the mode water formation rates. The formation rates are found by using the Speer and Tziperman [1992] formulation,

$$
\begin{aligned}
F(\rho)= & \frac{1}{\Delta \rho} \sum_{n=1}^{12} \Delta t(n) \sum_{i, j} A_{i, j} \\
& \cdot\left[\frac{-\alpha H_{i, j}(n)}{C_{p}}+\rho(S=0, T) \beta \frac{\left(E_{i, j}(n)-P_{i, j}(n)\right) S}{1-S}\right] \Pi(\Delta \rho) .
\end{aligned}
$$

Here, $\alpha=-(\partial \rho / \partial T) / \rho$ is the coefficient of thermal expansion, $\beta=(\partial \rho / \partial S) / \rho$ is the coefficient of haline contraction, $T$ is the sea surface temperature, $S$ is the sea surface salinity, $A$ is the area of grid point $(i, j), \Delta t(n)$ is the time step between months $n-1$ and $n, H$ is the heat flux into the ocean, $E$ is the evaporation, $P$ is the precipitation, $C_{p}$ is the specific heat, and $\Pi(\Delta \rho)$ is a boxcar of width $\Delta \rho$ (taken to be one-fifth of the potential density range listed in Table 3 ) over just the outcropping densities $(\rho)$ of the mode water mass. The formation rates are finally calculated offline with $-d F(\rho) / d \rho$.

\subsection{How to Make Use of Imperfect Model Output: Bayesian Model Averaging (BMA)}

[21] Since no single model simulation is perfect, a better estimate of the quantity of interest can be achieved by weighting model outputs based on comparisons with observations. By applying BMA, we can also determine the uncertainties associated with the subduction rate estimates. To do this, we need to decide, a priori, which model parameters we are uncertain about (which here are $\kappa_{H}$ and the circulation fields) but affect the quantity of interest (which here are the mean residence times and formation/subduction/ entrainment/detrainment rates). These model parameters need to be varied to span a realistic range of values they can take. Model agreement with the measured CFC-11 concentrations is chosen as a surrogate performance measure of each model simulation. Using BMA, we can estimate a 
Models including all errors

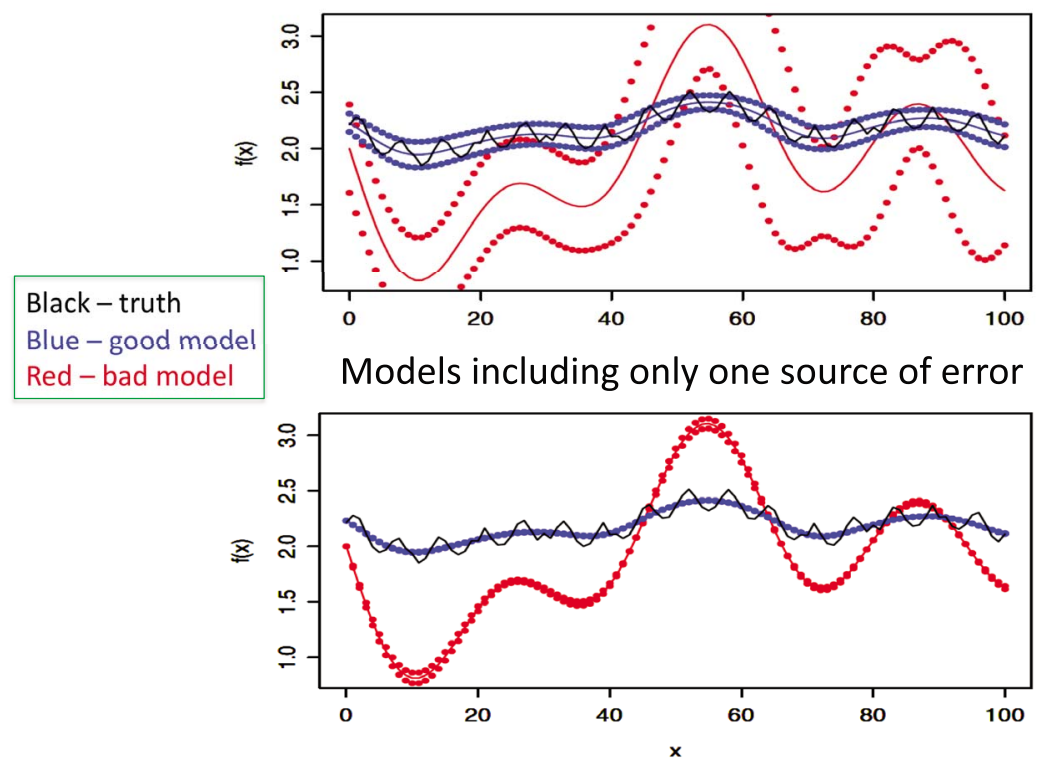

Figure 2. (top) The 95\% confidence intervals (dots) taking all sources of uncertainty (parameters in the deterministic function) into account and (bottom) the $95 \%$ confidence intervals (dots) taking only one of the sources of uncertainty into account using a deterministic function that we call 'truth' (solid black), an approximation that filters out the higher frequencies (solid blue), and a crude approximation that intersects the truth least often (solid red).

quantity of interest. BMA basically treats the model simulations as random variables and places a probability density on these random variables with a peak located at the model simulation that reproduces the observations most closely. Two main applications of BMA are 1) to perform model evaluation and 2) to find a best estimate with an uncertainty informed by observations. We will be doing the latter here.

[22] Two comments on estimating a quantity with a physical model are worth emphasizing: 1) a good physical model of the quantity of interest is needed and 2) the uncertainty associated with the model parameters that are the least well known and have a large impact on the model results needs to be incorporated. The uncertainty of an estimated quantity attributed to these model parameters should overwhelm the uncertainty attributed to other model parameters. For instance, a model that is not very accurate in the first place does not necessarily have point-wise uncertainty estimates that contain the 'truth' because it is neither accurate nor precise (Figure 2, top). Furthermore, failing to take all sources of uncertainty into account using a model that does well on average over periodic intervals of time will lead to point-wise uncertainty estimates that do not contain the truth either (Figure 2, bottom). We assume here that two quantities that are primarily responsible for determining transient tracer concentrations and are imperfect are the circulation fields and the alongisopycnal diffusivity parameter, $\kappa_{H}$. While BMA will not allow us to find a point estimate of the truth if our model is inadequate, we assume that by varying enough of the model's parameters and inputs we are able to calculate uncertainties of our estimates which contain the truth to $95 \%$ confidence. We also acknowledge that there are other parameters that likely have an influence on the results which we are not varying here due to the large computational expense. We would need to run HIM multiple times to vary the diapycnal diffusivity, for instance.

[23] The CFC-11 model simulations (see section 2.1.1) and the CFC-11 observations from the upper 1000 meters of all occupations listed in Table 1 across a given basin are used to compute the BMA weights with (A6) and (A7) according to the procedure described in Appendix A. For the Southern Ocean, each occupation of SR03, I09, P16, and A21 in the Drake Passage at each location and depth above 1000 meters was used in the likelihood, (A2) (i.e., the probability of the data given the model configuration). For the Subtropical North Atlantic Ocean, each occupation of A05 and A20 at each location south of $40^{\circ} \mathrm{N}$ above 1000 meters depth was used. For the Subpolar North Atlantic Ocean, each occupation of A16 and A20 at each location north of (and including) $40^{\circ} \mathrm{N}$ above 1000 meters depth was used. The final BMA weights are given for each basin in Table 4.

[24] Using the BMA weights, we finally arrive at the subduction rate estimates and their uncertainties with the following procedure. The model thickness, temperature, and salinity in this study are used to locate where the mode water masses in the North Atlantic and Southern Oceans are (see section 2.1.2). Subduction rates using the detrainment/ entrainment velocity-based method are then computed using the HIM diapycnal flux fields. Subduction rates using the TTD-based method are computed using the Offtrac BIR TTD estimates. For each model configuration (three different values of $\kappa_{H}$ and either climatological or hindcast fields), we average the BIR TTDs together and calculate a TTDbased subduction rate estimate from (2). The BMA weights 
Table 4. The Posterior Probabilities, $m_{j}$, Using a Uniform Prior, $P\left(M_{j}\right)=1 / 6(j=1, \ldots, 6)$, for the Six Configurations of AlongIsopycnal Diffusivity, $\kappa_{H}$, and Hindcast/Climatological Fields for Both the Southern Ocean (SO) Using the Upper $1000 \mathrm{~m}$ of I09, SR03, P16, and A21; the Subtropical North Atlantic (STNA) Using the Upper $1000 \mathrm{~m}$ of A05 and A20 (South of $40^{\circ} \mathrm{N}$ ); and the Subpolar North Atlantic (SPNA) Using the Upper $1000 \mathrm{~m}$ of A20 (North of $40^{\circ} \mathrm{N}$ ) and A16

\begin{tabular}{lcccc}
\hline \multirow{2}{*}{$\begin{array}{c}\text { Circulation } \\
\text { Fields }\end{array}$} & & \multicolumn{3}{c}{$m_{j}$} \\
\cline { 3 - 5 } & $\kappa_{H}$ & SO & STNA & SPNA \\
\hline Climatology & $5.0 \times 10^{2}$ & 0.180 & 0.205 & 0.248 \\
Hindcast & $5.0 \times 10^{2}$ & 0.165 & 0.130 & 0.0837 \\
Climatology & $1.0 \times 10^{3}$ & 0.177 & 0.203 & 0.246 \\
Hindcast & $1.0 \times 10^{3}$ & 0.154 & 0.133 & 0.0901 \\
Climatology & $1.0 \times 10^{4}$ & 0.172 & 0.199 & 0.244 \\
Hindcast & $1.0 \times 10^{4}$ & 0.153 & 0.129 & 0.0873 \\
\hline
\end{tabular}

determined by six Offtrac simulations of CFC-11 that use three different values of $\kappa_{H}$ and either climatological or hindcast fields are then applied. Each year, $t_{0}=1959,1964$, $1969, \ldots, 2004,2005$, a detrainment/entrainment velocitybased subduction rate estimate is calculated from (4) and the BMA weights determined by the Offtrac simulations that use either climatological or hindcast fields. Altering the along-isopycnal diffusivity in Offtrac does not affect the entrainment/detrainment velocity-based subduction rate estimates, but does affect the TTD-based subduction rate estimates (see section 2.1.1). The BMA weights are also used to estimate mean residence times, formation rates, and their uncertainties. The mean residence times are estimated by using the first cumulative moment of the averaged BIR TTD estimates and the formation rates are estimated by using the rate at which (5) changes over the density class of each mode water mass listed in Table 3.

\section{Results}

[25] The simulated CFC-11 concentrations from Offtrac in this study are used to determine which model simulations perform more closely to observations. This determines the BMA weights. We tried using two different prior distributions: $\left[P\left(M_{1}\right), P\left(M_{2}\right), P\left(M_{3}\right), P\left(M_{4}\right), P\left(M_{5}\right)\right.$, $\left.P\left(M_{6}\right)\right]=[0.050,0.125,0.150,0.500,0.050,0.125]$ (chosen because the higher probabilities are for values closer to the default configuration, $\kappa_{H}=10^{3} \mathrm{~m}^{2} \mathrm{~s}^{-1}$ with climatological fields used in Deutsch et al. [2011]), and [1/6, 1/6, $1 / 6,1 / 6,1 / 6,1 / 6]$. Here, $M_{1}, M_{3}$, and $M_{5}$ use the climatological circulation fields; $M_{2}, M_{4}$, and $M_{6}$ use the hindcast fields; $M_{1}$ and $M_{2}$ use $\kappa_{H}=5.0 \times 10^{2} \mathrm{~m}^{2} \mathrm{~s}^{-1} ; M_{3}$ and $M_{4}$ use $\kappa_{H}=1.0 \times 10^{3} \mathrm{~m}^{2} \mathrm{~s}^{-1}$; and $M_{5}$ and $M_{6}$ use $\kappa_{H}=1.0 \times 10^{4} \mathrm{~m}^{2} \mathrm{~s}^{-1}$. We found no distinguishable difference in the estimates of the BMA weights, $m_{j}$, by using different prior distributions.

\subsection{CFC-11 Objectively Mapped From Observations and Output From Offtrac}

[26] When applying Bayesian analysis in which a 'best' model is weighted more than the others, an implicit assumption is made that there is at least one model in the suite of possible models (combinations of climatological and hindcast circulation fields with three different values for $\kappa_{H}$ in the current study) that simulates reality reasonably well. If, for instance, in the current study, the CFC-11 concentrations simulated by Offtrac were nothing like the observed CFC-11 concentrations and were approximately constant as functions of latitude and longitude, linearly increasing as a function of depth, then our Offtrac simulations would not provide information about important features such as the structure of the mixed layer and/or spatial distribution of water masses.

[27] Here, we show an example map of CFC-11 concentrations according to Offtrac and from objectively mapping observations along I09 (Figure 3). Important to note is that the CFC-11 concentrations are smaller in some model configurations than in the observations and larger in other model configurations than in the observations. This implies that a weighted sum of these CFC-11 concentrations can be found to yield CFC-11 concentrations (Figure $3 \mathrm{~b}$ ) that are closer to the observations (Figure 3a) than any individual model simulation (Figures $3 \mathrm{c}-3 \mathrm{~h}$ ). The weights along I09 (Table 4) are those estimated by using the Southern Ocean transects (Table 1). Using the hindcast circulation fields with $\kappa_{H}=1 \times 10^{3} \mathrm{~m}^{2} \mathrm{~s}^{-1}$ yields CFC-11 concentrations closest to those from the objectively mapped observations along I09 (Table 5), but using the climatological circulation fields with $\kappa_{H}=1 \times 10^{3} \mathrm{~m}^{2} \mathrm{~s}^{-1}$ yields CFC-11 concentrations closest to those from the objectively mapped observations along most of the Southern Ocean transects (not shown). This explains why the BMA weights calculated from the Southern Ocean transects (Table 4) are largest for the model configuration that uses climatological circulation fields with $\kappa_{H}=1 \times 10^{3} \mathrm{~m}^{2} \mathrm{~s}^{-1}$.

[28] The BMA estimates of CFC-11 concentrations (Figure $3 \mathrm{~b}$ ) are mostly improved north of $50^{\circ} \mathrm{S}$ between the mixed layer depth and 1000 meters depth, but the CFC-11 concentrations are also improved over all depths using a root-mean-square error metric (Table 5). The contours of the CFC-11 concentrations from BMA are closer to the less steep vertical concentration gradient in the observations between $50^{\circ}-60^{\circ} \mathrm{S}$ than in the $\kappa_{H}=10^{4} \mathrm{~m}^{2} \mathrm{~s}^{-1}$ simulations. The $\kappa_{H}=10^{4} \mathrm{~m}^{2} \mathrm{~s}^{-1}$ simulations penetrate CFC-11 more deeply than the other simulations, but at the expense of errors in the vertical concentration gradient and at the surface (Figures 3e and 3h). Within the mixed layer and where there is SAMW (Figures 3a-3b), Offtrac is close enough with observations to have its output used, but is not close enough (particularly, near AABW) to provide much information at deeper depths.

\subsection{Water Mass Thicknesses by Basin}

[29] We identify SAMW, STMW, and SPMW with the potential vorticity and density ranges as listed in Table 3 from the HIM output. The thicknesses of SAMW, STMW, and SPMW according to the model hindcast (Figures $4 \mathrm{a}$, $4 \mathrm{c}$, and $4 \mathrm{e}$ ) are similar in spatial distribution to previous estimates [Sallée et al., 2006; Hall et al., 2007; Brambilla et al., 2008]. In the Southern Ocean, there is one notable difference between the mode water found in the model hindcast fields and the findings of Sallée et al. [2006, Figure 13b]. There is the dearth of SAMW in the Indian Ocean in the model hindcast fields. In the North Atlantic Ocean, on the other hand, the regions where there are maxima in annual mean (North Atlantic) STMW (Figure 4c) and 

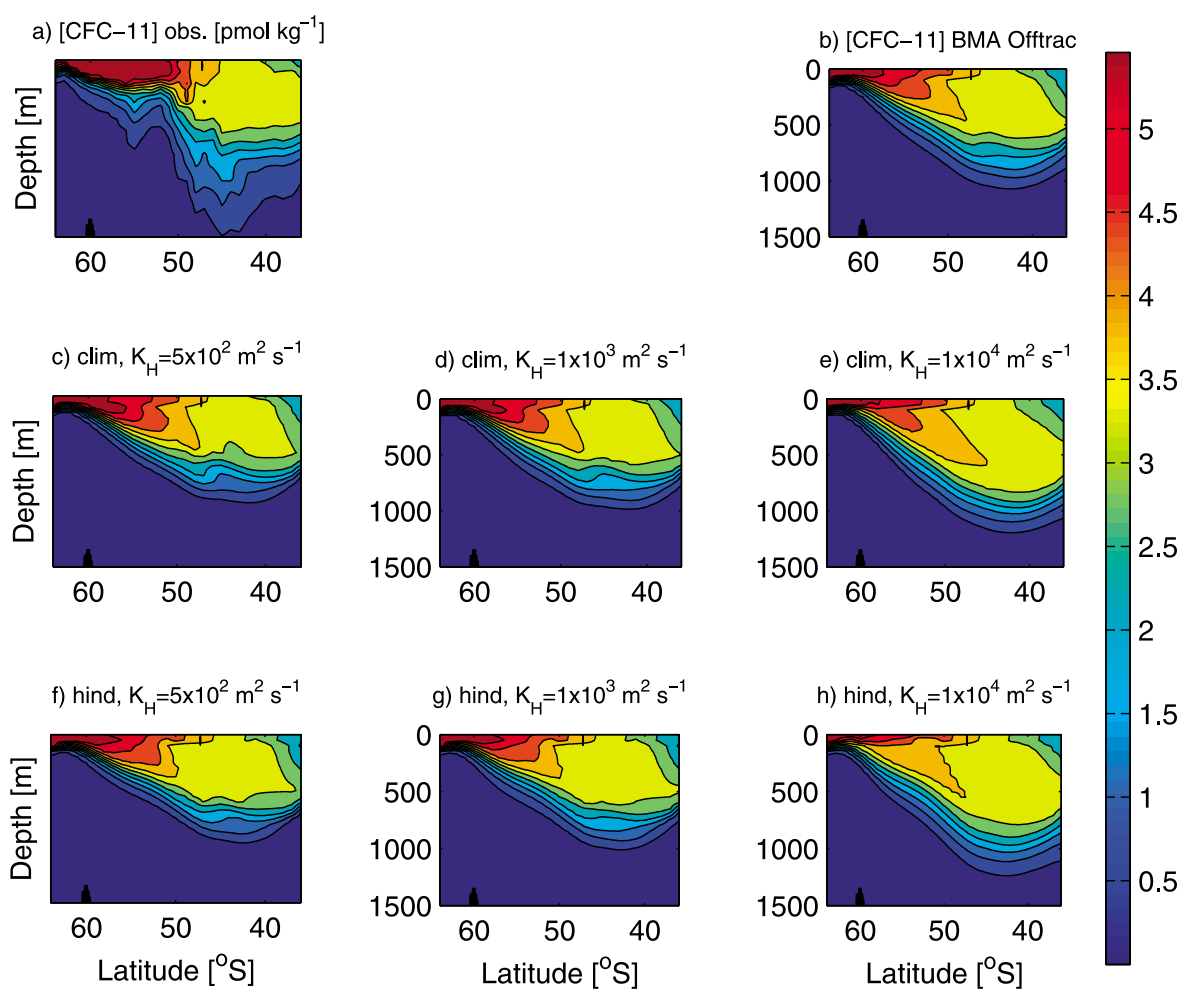

Figure 3. Comparison plots of CFC-11 concentrations [pmol kg-1] (a) along I09 in 1995 from objectively mapped observations and (b) weighting each of the six Offtrac runs by BMA-derived posterior probabilities and $(\mathrm{c}-\mathrm{h})$ each of the Offtrac runs using either climatological or hindcast circulation fields and three different values for $\kappa_{H}$. The root-mean-square errors from the objectively mapped observations for Figures $3 \mathrm{~b}-3 \mathrm{~h}$ are listed in Table 5.

SPMW (Figure 4e) thicknesses, as seen in Maze and Marshall [2011, Figure 1] and Brambilla et al. [2008, Figure 1], are replicated here.

[30] The standard deviations of the winter thicknesses of each mode water mass are also shown in Figure 4. Winter SAMW thickness varies most between Tasmania and New Zealand. Winter STMW thickness varies most around the Gulf Stream and almost not at all between $20^{\circ}-30^{\circ} \mathrm{N}$. Winter SPMW thickness varies most around the East Greenland Current, in the overflow regions flanking Iceland, and near the North Atlantic Current.

\subsection{Volume Transport and Mass Fraction Erosion Spectra}

[31] The volume transport spectrum of SAMW, STMW, and SPMW (Figures 5a, 5c, and 5e) inferred using (2) represents the rate at which each mode water mass is being ventilated in the thermocline as a function of how long the mode water has resided beneath the mixed layer, and where it is not in direct contact with the atmosphere. Estimates of the uncertainties, resulting from the TTDs calculated with different boundary impulse initialization times, in the volume transport spectra (dashed lines in Figures 5a,

Table 5. The Root-Mean-Square Errors (RMSE) and Mean CFC-11 Concentrations $\left(\overline{[C F C 11}_{\text {model }}\right)$, Both in pmol kg ${ }^{-1}$, Along I09 for Each of the Model Configurations ${ }^{\mathrm{a}}$

\begin{tabular}{lccccc}
\hline $\begin{array}{l}\text { Circulation } \\
\text { Fields }\end{array}$ & $\kappa_{H}$ & $\begin{array}{c}\text { All Depths } \\
\text { RMSE }\end{array}$ & $\begin{array}{c}\text { All Depths } \\
{[C F C 11]_{\text {model }}}\end{array}$ & $\begin{array}{c}\text { Upper 1000 } \mathrm{m} \\
\text { RMSE }\end{array}$ & $\begin{array}{c}\text { Upper 1000 m } \\
{[C F C 11]_{\text {model }}}\end{array}$ \\
\hline Climatology & $5.0 \times 10^{2}$ & 0.485 & 0.550 & 0.752 & 2.05 \\
Hindcast & $5.0 \times 10^{2}$ & 0.467 & 0.547 & 0.709 & 2.03 \\
Climatology & $1.0 \times 10^{3}$ & 0.467 & 0.574 & 0.716 & 2.13 \\
Hindcast & $1.0 \times 10^{3}$ & 0.447 & 0.570 & 0.671 & 2.11 \\
Climatology & $1.0 \times 10^{4}$ & 0.508 & 0.671 & 0.844 & 2.44 \\
Hindcast & $1.0 \times 10^{4}$ & 0.464 & 0.657 & 0.748 & 2.37 \\
BMA & BMA & 0.434 & 0.594 & 0.654 & \\
\hline
\end{tabular}

${ }^{\mathrm{a}}$ Given are either climatological or hindcast circulation fields and a single value for $\kappa_{H}$, shown in Figures $3 \mathrm{c}-3 \mathrm{~h}$. Also given are the BMA weighted output (both circulation fields, all $\kappa_{H}$ ) shown in Figure $3 \mathrm{~b}$. The mean CFC-11 concentrations from the objectively mapped observations are 0.733 pmol kg ${ }^{-1}$ over all depths and $2.17 \mathrm{pmol} \mathrm{kg}^{-1}$ in the upper $1000 \mathrm{~m}$. 


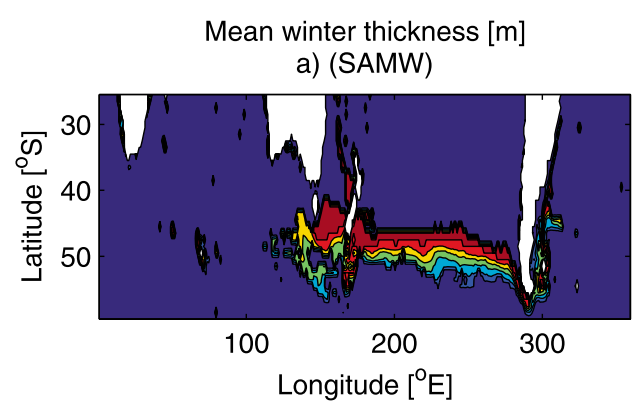

c) (STMW)

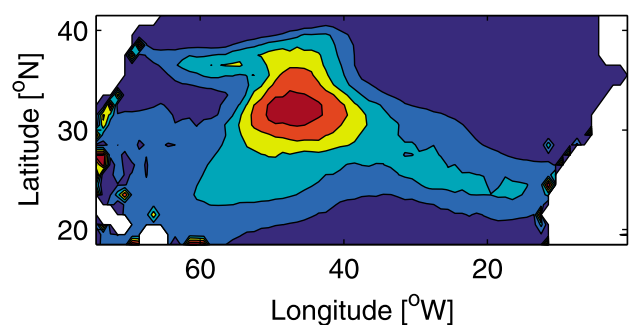

e) (SPMW)

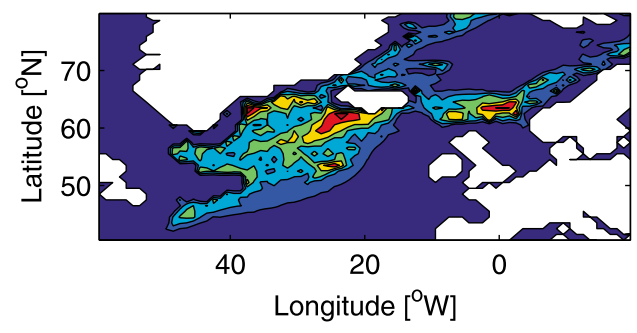

Std. winter thickness [m]

b) (SAMW)

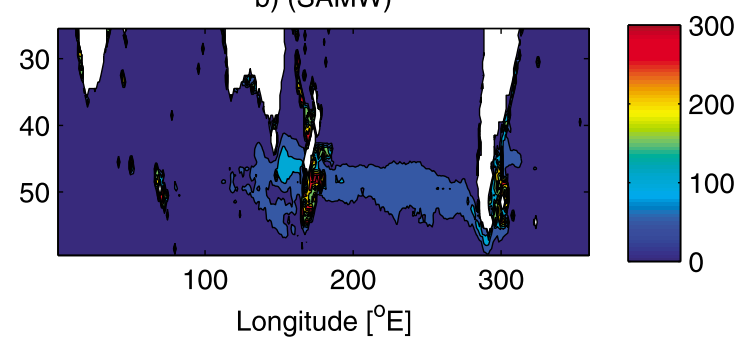

d) (STMW)
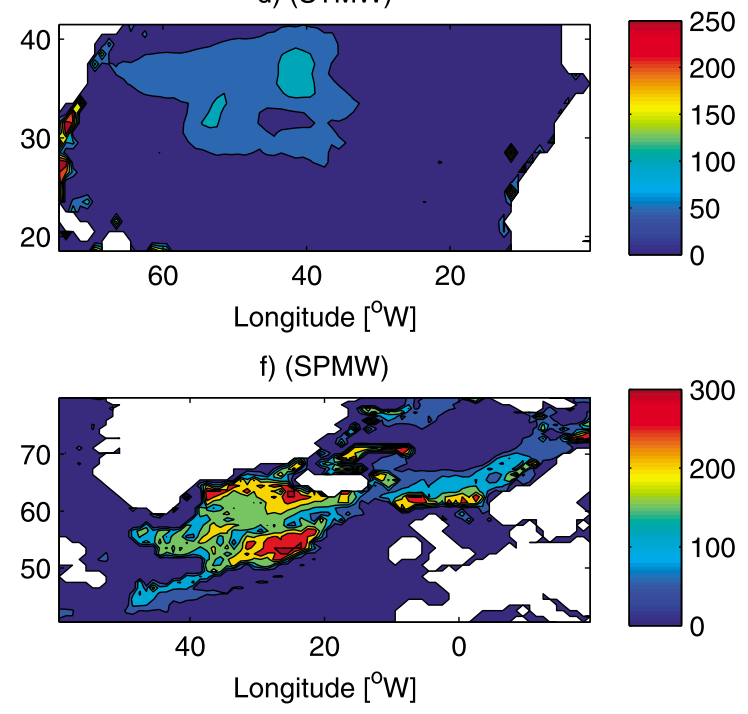

Figure 4. The average mode water thickness in the water column at each horizontal location in March (North Hemisphere) or September (Southern Hemisphere) of the entire 47 years of the hindcast in the (a) Southern, (c) Subtropical North Atlantic, and (e) Subpolar North Atlantic Oceans. Also plotted are the standard deviations about the average mode water thickness in the water column at each horizontal location over the entire 47 years of the hindcast in the (b) Southern, (d) Subtropical North Atlantic, and (f) Subpolar North Atlantic Oceans. At a given location, a larger standard deviation of thickness than mean thickness implies a large thickness at some times and a very small thickness at other times.

5c, and 5e) vary for the three mode water masses. The temporal variability in the volume transports of STMW (Figure 5c) is greater than that of SAMW (Figure 5a) or SPMW (Figure 5e). SAMW has a mode in its volume transport spectrum at about 5 years (Figure 5a), while STMW has a mode in its volume transport spectrum at 0 years (Figure 5c) and SPMW has a mode in its volume transport spectrum at a few years (Figure 5e).

[32] A residence time estimate is calculated from the first cumulative moment of the normalized volume transport spectrum (Table 6). The residence times have 95\% confidence intervals also listed in Table 6 that incorporate both uncertainties from BMA and temporal variability. The residence time of SAMW is longest and has the largest confidence interval widths (Table 6), followed by SPMW, and finally STMW. It has been noted [Hall et al., 2007] that previous studies have focused on the younger age part of the spectrum of residence times. Since there is no STMW in the North Atlantic Ocean with ages above 75 years, there is no difference between the mean residence times of STMW using the full volume transport spectrum and the mean residence times of STMW using a truncated volume transport spectrum at 75 years. We find a mean residence time (with
$95 \%$ confidence interval) of $3.92(2.06,5.78)$ years for STMW which is similar to an observationally-derived estimate of 3.57(3.03, 4.11) years [Kwon and Riser, 2004] and a more recent estimate of 3.54 years from a data assimilation state estimate [Maze and Marshall, 2011]. For SPMW and SAMW, however, a younger mean residence time (Table 6) stems from truncating the TTD to the youngest 75 years, the amount of time CFC-11 has been entering the ocean. Furthermore, mean residence times of the three mode water masses considered here are biased young by different amounts due to varying amounts of mixing of water parcels with varying amounts of TTD truncation at different locations (not shown).

[33] To investigate whether our residence time estimates using the full volume transport spectra are of the order of magnitude implied by using a background diapycnal diffusivity, $K$, found in previous studies [Goes et al., 2010; Polzin et al., 1997, Table 1; Kunze et al., 2006, Figure 11] and thicknesses, $H_{m w}$, of each mode water mass found in the HIM hindcast fields at each horizontal grid point, we perform a scaling argument to find the residence time with the average value of $H_{m w}^{2} / K$. The three values of $K$ used here for the three mode water masses are listed in Table 6 . The 
Volume transport spectrum

a) (SAMW)
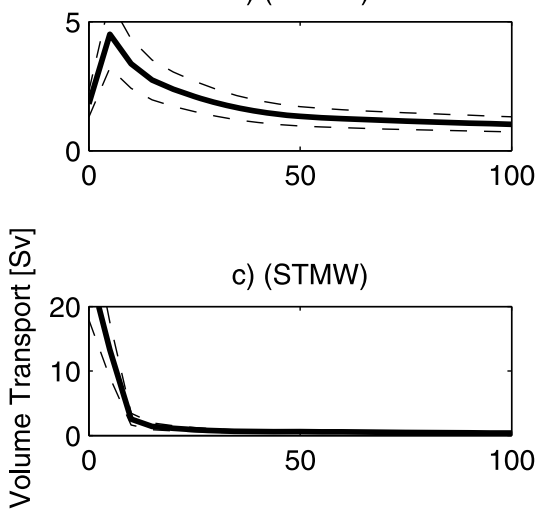

e) (SPMW)

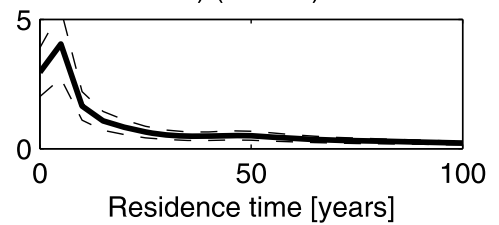

Mass fraction eroded

b) (SAMW)
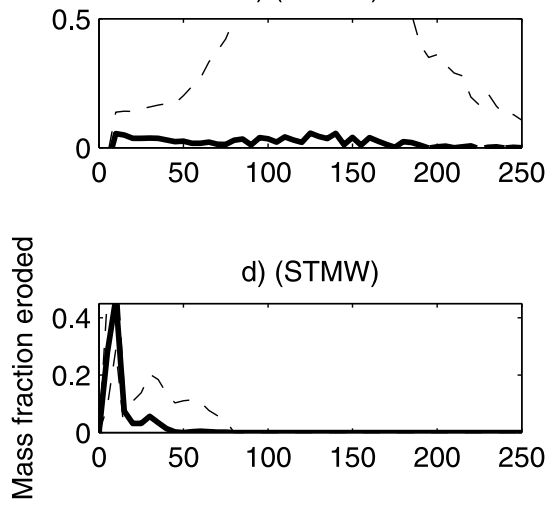

f) (SPMW)

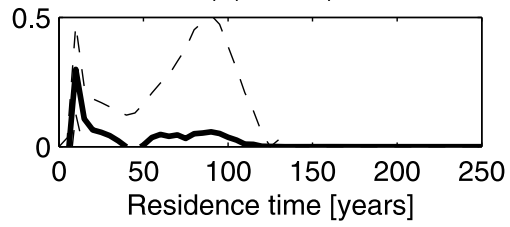

Figure 5. (a, c, and e) The volume transport spectra $\left[\mathrm{Sv}=10^{6} \mathrm{~m}^{3} \mathrm{~s}^{-1}\right]$ and $(\mathrm{b}, \mathrm{d}$, and $\mathrm{f}$ ) mass fractions eroded (solid lines) and their variability over time (dashed lines) of Subantarctic Mode Water (Figures 5a and 5b), Subtropical Mode Water (Figures 5c and 5d), and Subpolar Mode Water (Figures 5e and 5f) for years 1959 through 2005. The peak in the variability of the mass fraction erosion spectrum of SAMW is off the scale because is it easier to see the magnitude of the spectrum (solid line in Figure 5b) on the scale that is shown.

scaling argument residence time estimates are the same order of magnitude as the residence time estimates using the full volume transport spectrum for all three mode water masses (Table 6). This result suggests turbulent mixing (below the mixed layer) is a significant mode water mass erosion mechanism, but it may be more important for some mode water masses than others. We will come back to this issue in section 3.5 .

[34] Using (3), we also find the mass fractions of SAMW, STMW, and SPMW that erode as a function of residence time (Figures 5b, 5d, and 5f). There are significant amounts of non-zero fractions with residence times that exceed 100 years for SAMW and SPMW(Figures 5b and 5f), which suggests that these mode waters are partially composed of waters that get recycled and stay beneath the mixed layer for long periods of time. The mode of the average mass fraction erosion spectrum of SAMW is a few years, but there is a second mode between 100-150 years with the most variability between 100-200 years of any mode water mass investigated here (Figure 5b). The mode of the mass fraction erosion spectrum of STMW is a few years with a secondary peak at 35-45 years (Figure $5 \mathrm{~d}$ ). The mode of the mass fraction erosion spectrum of SPMW is a few years with a secondary peak at 60-90 years (Figure 5f). One explanation for the large peak in the variability of the mass fraction erosion spectrum of SAMW is that transformations of SAMW to other water masses (e.g., AAIW) contribute significantly to the erosion of SAMW, and this occurs more during some years than others. Another explanation is that the erosion mechanism(s) acting on the time scales of the secondary peaks of the mass fraction erosion spectra can also contribute to mode water formation.

[35] The multiple peaks in the mass fraction erosion spectra (Figures 5b, 5d, and 5f) suggest there are erosion processes with at least two distinguishable timescales acting. There are many candidate processes responsible for mode water erosion that takes place on various timescales. Within a single year, mode water can be reentrained into the mixed layer. This process would correspond with the youngest of the peaks in the mass fraction erosion spectrum. Also over shorter timescales, mode water can be eroded via air-sea fluxes. Over several decades, the mode water can be eroded

Table 6. The Mode Water Residence Times for the Southern Ocean (SAMW), the Subtropical North Atlantic (STMW), and the Subpolar North Atlantic (SPMW), Calculated From the BMA Estimates of the Model TTDs (Full Volume Transport Spectrum) ${ }^{\mathrm{a}}$

\begin{tabular}{lccc}
\hline & \multicolumn{3}{c}{ Residence Time (yrs) } \\
\cline { 2 - 4 } Water & $\begin{array}{c}\text { Full Volume } \\
\text { Mass }\end{array}$ & $\begin{array}{c}\text { Volume Transport } \\
\text { With Truncation }\end{array}$ & $\begin{array}{c}\text { Scaling } \\
\text { Argument }\end{array}$ \\
\hline SAMW & $47.6(39.2,56.0)$ & $26.9(24.7,29.2)$ & 84.3 \\
STMW & $3.92(2.06,5.78)$ & $3.92(2.06,5.78)$ & 6.50 \\
SPMW & $20.6(16.2,25.1)$ & $17.8(15.2,20.3)$ & 16.2 \\
\hline
\end{tabular}

${ }^{\mathrm{a}}$ Also listed are the residence times calculated by truncating the TTD after 75 years (with truncation) and residence times by using the average ratio of the squared mode water thickness to background diapycnal diffusivity (scaling argument). The scaling argument assumes a background diapycnal diffusivity, $K$, found to be typical of the Southern Ocean thermocline, $0.2 \mathrm{~cm}^{2} \mathrm{~s}^{-1}$ [Goes et al., 2010]; a mid-range value for a western boundary region of the North Atlantic Ocean, $0.5 \mathrm{~cm}^{2} \mathrm{~s}^{-1}$ [Polzin et al., 1997, Table 1]; and a value inferred above the Rockall Plateau along the northern end of A16, $0.25 \mathrm{~cm}^{2} \mathrm{~s}^{-1}$ [Kunze et al., 2006, Figure 11]. 
Table 7. The Mode Water Subduction Rates for the Southern Ocean (SAMW), the Subtropical North Atlantic (STMW), and the Subpolar North Atlantic (SPMW) for Each of the Model Configurations of Circulation Fields and $\kappa_{H}{ }^{\mathrm{a}}$

\begin{tabular}{lcccr}
\hline \multirow{2}{*}{$\begin{array}{l}\text { Circulation } \\
\text { Fields }\end{array}$} & $\kappa_{H}$ & SAMW & TTD-Based Subduction Rate (Sv) \\
\cline { 3 - 5 } Climatology & $5.0 \times 10^{2}$ & 14.9 & STMW & SPMW \\
Hindcast & $5.0 \times 10^{2}$ & 24.0 & 4.34 & 2.80 \\
Climatology & $1.0 \times 10^{3}$ & 14.3 & 5.77 & 4.31 \\
Hindcast & $1.0 \times 10^{3}$ & 23.8 & 4.85 & 2.82 \\
Climatology & $1.0 \times 10^{4}$ & 12.9 & 6.21 & 4.40 \\
Hindcast & $1.0 \times 10^{4}$ & 22.7 & 4.87 & 4.91 \\
BMA & BMA & $16.7(9.96,23.5)$ & $5.62(3.71,7.53)$ & $2.30(1.42,3.18)$ \\
\hline
\end{tabular}

${ }^{a}$ Rates are calculated from the average of the model BIR TTD estimates over the 1959-2005 period, which is closer to the true model TTD. Also given are the final BMA weighted subduction rate estimates with $95 \%$ confidence intervals (both circulation fields, all $\kappa_{H}$ ).

due to turbulent mixing. Together, these processes span the entire mass fraction erosion spectrum. The relatively large primary peak in the mass fraction erosion spectra for STMW and SPMW suggest that the combination of entrainment back into the mixed layer and air-sea fluxes play a larger role in the destruction of North Atlantic mode waters than erosion due to turbulent mixing. The relatively flat mass fraction erosion spectrum for SAMW suggests that entrainment back into the mixed layer, air-sea fluxes, and erosion due to turbulent mixing could all play comparable roles in the destruction of SAMW. In section 3.5, we perform a more quantitative analysis of the contribution of these three erosion mechanisms for each of the three mode water masses considered here.

[36] Erosion processes give each mass fraction erosion spectrum a finite width (Figure 5). Formation of water masses away from the surface (e.g., below the mixed layer) could occur via diapycnal or eddy transport, which here are parameterized by the diapycnal diffusivity in HIM reflected in the diapycnal transport fields in Offtrac and the alongisopycnal diffusivity in Offtrac, respectively. The mass fraction erosion spectra have larger variability at longer timescales (Figures $5 \mathrm{~b}, 5 \mathrm{~d}$, and $5 \mathrm{f}$ ), primarily due to temporal variability and not due to the uncertainty from BMA. We can see this by setting the BMA weights for the model simulations with a certain $\kappa_{H}$ to zero and reweighting the remaining weights for the model simulation with other values for $\kappa_{H}$, we find little difference in the width of the area subsumed by the dashes lines in Figure 5, but we do find differences in the mean residence times and subduction rates (not shown). A larger along-isopycnal diffusivity yields longer tails in the volume transport spectra, shifts the 100 year peak in the SAMW mass fraction erosion spectrum to younger ages more than the secondary peaks of the STMW or SPMW mass fraction erosion spectra, and decreases the mean residence times, but the subduction rates do not always increase. Decreasing the along-isopycnal diffusivity yields shorter tails in the volume transport spectra, shifts the 100 year peak in the SAMW mass fraction erosion spectrum to older ages more than the secondary peaks of the STMW or SPMW mass fraction erosion spectra, and increases the mean residence times, but the subduction rates do not always decrease.

\subsection{Subduction Rate Estimates}

[37] Based on the BMA-derived posterior probabilities (Table 4) and using the TTD-based method, estimates of the subduction rates and their estimates' variances were computed.
The TTD-based subduction rates for each model configuration (of $\kappa_{H}$ and either climatological or hindcast circulation fields) are given in Table 7 as well as a final 'best' estimate after Bayesian model averaging all of the BIR TTDs starting at different times, $t_{0}$, to find an estimate that is closer to the true model TTD, using BMA to find the uncertainties. The circulation field exerts a large control on the subduction rate estimate with the variable (hindcast) fields leading to larger estimates for SAMW and SPMW, but smaller estimates for STMW. Thus, the circulation field makes the biggest difference in our subduction rate estimates, but changing the alongisopycnal diffusivity matters more for some ocean basins than others. A larger along-isopycnal diffusivity decreases the subduction rates of SAMW owing to the dilution of SAMW CFC-11 concentrations near the surface (Figures 3c-3h).

[38] For each of the three mode waters, a calculation based on the entrainment/detrainment velocities via (4) was also performed from 1959 to 2005 and is compared to a TTDbased estimate (Figures 6a, 6d, and $6 \mathrm{~g}$ ). The entrainment/ detrainment velocity-based estimates represent the formation of water in the mixed layer with subsequent advective subduction, but does not consider modification of the water mass once it is in the ocean interior. The differences between the entrainment/detrainment velocity-based estimates and the TTD-based estimates of subduction rates are that diffusion can enhance the subduction process and can also erode mode water below the mixed layer. Our estimates suggest that diffusion, on average, contributes to about $22.0 \%$ of SAMW subduction (Figure 6a), 32.0\% of STMW subduction (Figure $6 \mathrm{~d}$ ), and $2.64 \%$ to SPMW subduction (Figure $6 \mathrm{~g}$ ).

[39] The time series of entrainment/detrainment velocitybased estimates of subduction rates (Figures 6a, 6d, and 6g) suggest an increasing trend for each of the three mode water masses, although the trend is not significant at the $95 \%$ level. The trend in the entrainment/detrainment velocity-based estimates of subduction rates for SAMW, STMW, and SPMW are significant at the $25.0 \%, 62.5 \%$, and $30.0 \%$ levels, respectively. Unlike STMW formation, subduction contributes only a small fraction to SPMW formation (Figures $6 \mathrm{~d}$ and $6 \mathrm{~g}$ ) and is not directly related to windforcing [Brambilla et al., 2008] which makes it difficult to interpret the causes of the suggested increase in SPMW subduction. Stratification changes are one possible mechanism for changing subduction rates, but we do not pursue this in the current study. In the Southern Ocean, mixed layer depth anomalies are primarily determined by the Southern Annular Mode (SAM) and have been increasing [Sallée 
a) (SAMW)
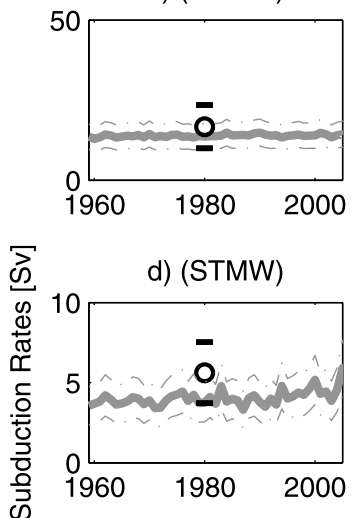

g) (SPMW)

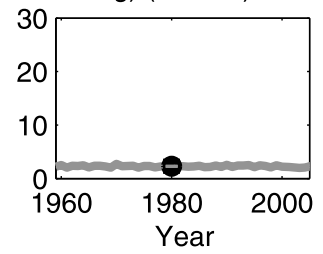

b) (SAMW)

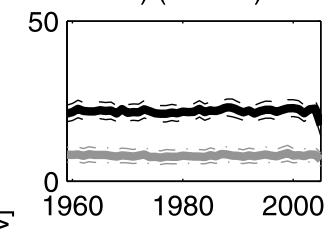

e) (STMW)

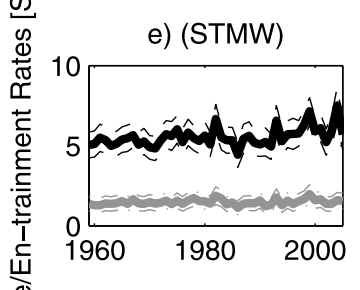

h) (SPMW)

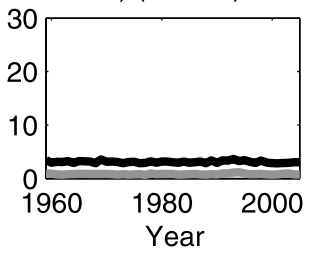

c) (SAMW)
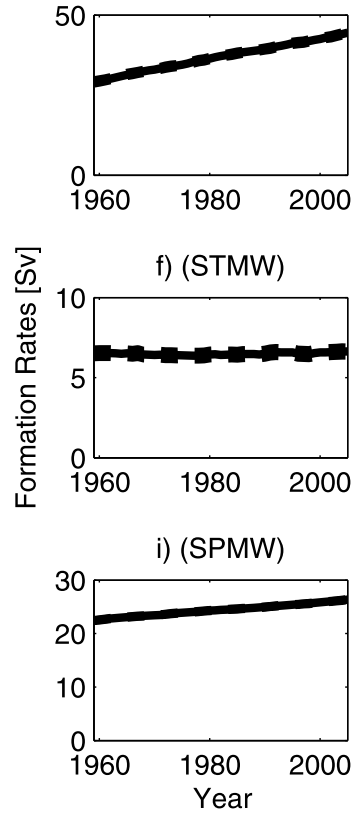

Figure 6. The subduction rates $\left[\mathrm{Sv}=10^{6} \mathrm{~m}^{3} \mathrm{~s}^{-1}\right]$ (TTD-based method in solid black circles and diapycnal velocity-based method in solid grey lines) with their approximate $95 \%$ confidence intervals derived from BMA estimate variances (short black bars for the TTD-based method and dot-dashed grey lines for the entrainment/detrainment velocity-based method) for (a) Subantarctic Mode Water, (d) Subtropical Mode Water, and (g) Subpolar Mode Water for years 1959 through 2005. (b, e, and h) The entrainment (grey lines) and detrainment (black lines) rates with (c, f, and i) their approximate 95\% confidence intervals and formation rates (black lines) of Subantarctic Mode Water, Subtropical Mode Water, and Subpolar Mode Water for years 1959 through 2005 with their approximate 95\% confidence intervals (dashed lines) are also shown.

et al., 2010]. This may partially explain the increase we find in the SAMW subduction rates (Figure 6a). Also, the finding that there has been a speed-up of the Subtropical Indian Ocean gyre [McDonagh et al., 2005] may partially explain the increase we find in the SAMW subduction rates.

[40] To investigate whether the NAO (from http:// www.cgd.ucar.edu/cas/jhurrell/indices.html) and SAM (from http://www.nerc-bas.ac.uk/icd/gjma/sam.html) are related to subduction rates on longer timescales, we correlate these climate indices with the entrainment/detrainment velocitybased subduction rates after removing each of their lowpassed time series trends. We lag the subduction rates by three years after the winter climate indices, as [Kwon and Riser, 2004] approximately did with STMW volume and the winter NAO index. We use two different techniques to remove the trends in each time series. One low-pass is performed by mirroring the time series both at its beginning and end and then applying a wavelet-based technique: we represent the time series with a Daubechies wavelet representation [Percival and Walden, 2000] and transform back to the time domain with a number of points equal to two less powers of two than the number of points in the raw time series. The other technique uses a five-year running average, centered on each year in which we have a subduction rate estimate. Neither the winter SAM index nor the winter NAO index explain the variability in the entrainment/detrainment velocitybased estimates of SAMW or SPMW subduction rates from 1959 to 2005 (Table 8). These results do not change with different lag times or use of annual, as opposed to winter, climate indices. However, interannual variability in the winter NAO index correlates well with that of the entrainment/ detrainment velocity-based estimates of STMW subduction rates (Table 8). This result is suggestive and consistent with the results of Kwon and Riser [2004] regarding the relationship between STMW and the NAO.

\subsection{Mode Water Formation and Erosion Mechanisms}

[41] Based upon the model results for 1959 to 2005, SAMW was formed between $45^{\circ}-60^{\circ} \mathrm{S}$ at south of Australia, south of Africa, in the Drake Passage, and in the southeastern Pacific (Figure 7a); STMW was formed between $35^{\circ}-40^{\circ} \mathrm{N}$

Table 8. Low-Pass Filtering Techniques $c_{\text {wavelet }}$ Using Two Dyadic Decompositions in the Wavelet Domain and $c_{\text {movingavg }}$ Using a 5-Year Moving Average Centered at the Year in Which There Is a Subduction Rate Estimate ${ }^{\text {a }}$

\begin{tabular}{lcc}
\hline Water Mass & $c_{\text {wavelet }}(\mathrm{p}$-Value $)$ & $c_{\text {movingavg }}(\mathrm{p}$-Value $)$ \\
\hline SAMW & $-0.155(0.300)$ & $-0.121(0.416)$ \\
STMW & $-0.439(0.0020)$ & $-0.450(0.0015)$ \\
SPMW & $-0.155(0.305)$ & $-0.148(0.327)$ \\
\hline
\end{tabular}

${ }^{\mathrm{a}}$ Listed are the Pearson correlations with p-values for the entrainment/ detrainment velocity-based subduction rates (low-passed trends removed) of three mode waters: Subantarctic Mode Water (SAMW), Subtropical Mode Water (STMW), and Subpolar Mode Water (SPMW), and their winter climate indices leading by three years (low-passed trends removed): the Southern Annular Mode (SAM) index for SAMW and the North Atlantic Oscillation (NAO) index for STMW and SPMW. 


\section{a) (SAMW)}

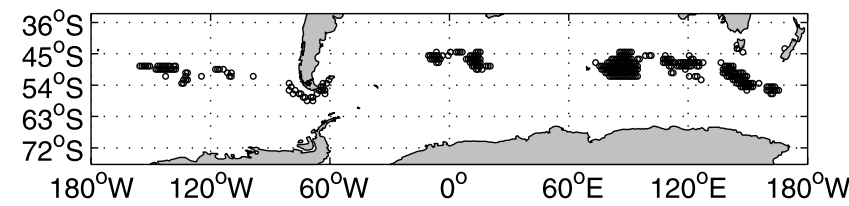

b) (STMW)

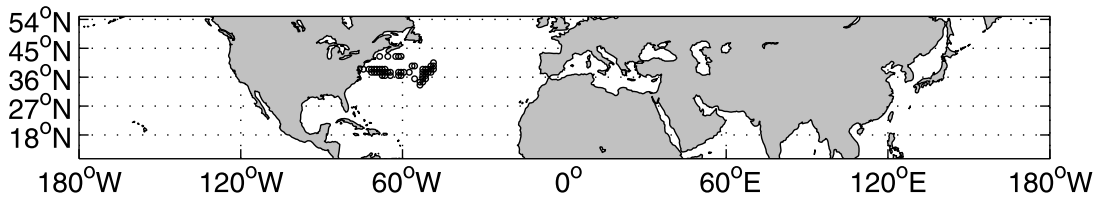

c) (SPMW)

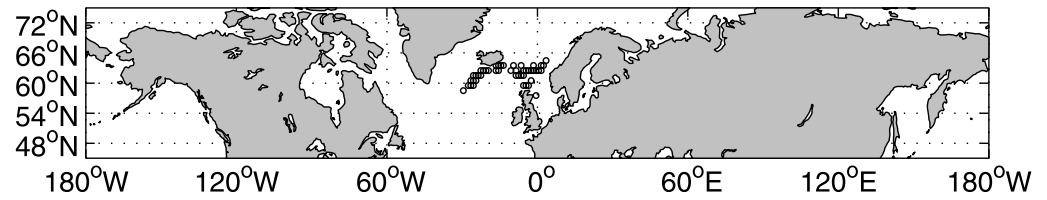

Figure 7. The locations (open black circles) of where the majority of (a) Subantarctic Mode Water, (b) Subtropical Mode Water, and (c) Subpolar Mode Water formation occurs, found by using the density ranges listed in Table 3 and the Speer and Tziperman [1992] formulation, via (5), for years 1959 through 2005.

around the Gulf Stream (Figure 7b); and SPMW was formed between $60-65^{\circ} \mathrm{N}$ primarily southeast of Iceland (Figure 7c). The average formation rate of SAMW is about $15 \mathrm{~Sv}$ in the South Pacific alone, which compares well with the findings of Hartin et al. [2011], and is about $35 \mathrm{~Sv}$ total, which is larger than the findings of Sloyan and Rintoul [2001]. The average formation rate of SPMW is about $24 \mathrm{~Sv}$, which is in the high end of the findings of Brambilla et al. [2008]. The average formation rate of STMW is found to be about $6 \mathrm{~Sv}$, which is comparable to what Forget et al. [2011] found.

[42] A comparison of the detrainment rates with the formation rates allow us to determine whether subduction is responsible for the majority of the formation of each mode water mass. The detainment rates (setting $w_{e n}=0$ in (4); black in Figures 6b, 6e, and 6h) are always larger than the entrainment rates (setting $w_{d e}=0$ in (4); grey in Figures 6b, $6 \mathrm{e}$, and $6 \mathrm{~h})$ ), and their difference is equal to the detrainment/ entrainment velocity-based subduction rate estimates (grey in Figures 6a, 6d, and 6g). Nearly all of the STMW in the North Atlantic Ocean that is formed is detrained out of the mixed layer, but less than half of the SPMW in the North Atlantic Ocean that is formed is detrained out of the mixed layer which can be seen by comparing the detrainment rates (black in Figures 6e and 6h) with the formation rates calculated from (5) (black in Figures $6 \mathrm{f}$ and 6i). The rate at which SAMW in the Southern Ocean is detrained (black in Figure 6b) relative to formed (black in Figure 6c) has been getting smaller with time. The difference between the detrainment rates and formation rates of SAMW (Figures $6 \mathrm{~b}$ and $6 \mathrm{c}$ ) is larger than that of STMW (Figures 6e and 6f), with the formation of the latter almost entirely owing to subduction. Also, it should be pointed out that the detrainment rates (black in Figures 6b, 6e, and 6h) are always very close to and never less than the TTD-based subduction rates (black in Figures 6a, 6d, and 6g).

[43] Attributing the differences between the detrainment rates and formation rates to specific processes will not be pursued here, but there are candidate processes described in previous studies. The TTD approach can capture the transformation of SAMW into AAIW [Sloyan et al., 2010] and the conversion of AAIW and UCDW into SAMW [Downes et al., 2011] via cabbeling and thermobaricity. However, these processes may not be sufficiently well represented in HIM/Offtrac because of its model resolution to explain the increasingly significant amount of SAMW formed by processes other than subduction (Figures 6a-6c). While overflow waters are also not well represented in HIM/Offtrac because of its resolution, the relatively large difference between the detrainment rates and formation rates of SPMW suggests that most SPMW is formed by processes other than subduction (Figures 6g-6i). Brambilla et al. [2008] suggest that diapycnal fluxes are mostly responsible for the formation of SPMW, which is consistent with the difference between detrainment and formation rates we find here.

[44] Lastly, by comparing the average entrainment rates with the average formation rates of each mode water mass over 1959 to 2005 and calculating the fraction of area under the mass fraction erosion spectra that are on longer timescales, we can determine whether the majority of the erosion of each mode water mass is due to entrainment back into the mixed layer or turbulent mixing (Table 9). For both SAMW and STMW, the entrainment rates (grey in Figures $6 \mathrm{~b}$ and $6 \mathrm{e}$ ) are about $20 \%$ of their formation rates (black in Figures $6 \mathrm{c}$ and $6 \mathrm{f})$. For SPMW, on the other hand, the entrainment rate (grey in Figure $6 \mathrm{~h}$ ) is less than 5\% of its formation rate (black in Figure 6i). This suggests that the majority of SAMW, 
Table 9. The Average Fraction of Mode Water Erosion Rates for the Southern Ocean (SAMW), the Subtropical North Atlantic (STMW), and the Subpolar North Atlantic (SPMW) over 1959 to 2005 That Can Be Attributed to Entrainment Back Into the Mixed Layer $^{\mathrm{a}}$

\begin{tabular}{lccc}
\hline $\begin{array}{c}\text { Erosion } \\
\text { Mechanism }\end{array}$ & SAMW & STMW & SPMW \\
\hline Entrainment & $21.2 \%$ & $23.1 \%$ & $3.39 \%$ \\
Turbulent mixing & $70.6 \%$ & $11.8 \%$ & $48.0 \%$ \\
\hline
\end{tabular}

${ }^{a}$ Values for entrainment are calculated using the ratio of the entrainment rates to formation rates and values for turbulent mixing below the mixed layer are calculated using the fraction of area under the mass fraction erosion spectrum that is not under the first peak.

STMW, and SPMW erosion occurs due to turbulent mixing or air-sea fluxes.

[45] To investigate whether turbulent mixing is the dominant erosion mechanism for each mode water mass, we can estimate the fraction of mode water that erodes over relatively long timescales by calculating the fraction of area (from integration) under the first peak of each mass fraction erosion spectrum, $f_{\text {young }}$, and subtracting this fraction from one. If we assume that turbulent mixing is primarily responsible for the non-zero fraction of area under each mass fraction erosion spectrum at relatively large residence times, $1-f_{\text {young }},(>60$ years for SAMW, $>25$ years for STMW, and $>45$ years for SPMW; see Figures $5 \mathrm{~b}, 5 \mathrm{~d}$, and $5 \mathrm{f}$ and Table 9), then we find that there is a significant amount of STMW and SPMW erosion due to air-sea fluxes. Under this assumption, we find that about two-thirds of STMW erodes due to air-sea fluxes, which is consistent with the findings of Forget et al. [2011], and about half of SPMW erodes due to air-sea fluxes. Our results also suggest that very little SAMW erodes due to air-sea fluxes. The mean residence time estimates for each of the three mode water masses considered here using our scaling argument are all larger than the mean residence time estimates from the first cumulative moment of the average model TTD (Table 6) because turbulent mixing is not responsible for $100 \%$ of the mode water erosion. Also, the value of $K$ that we used for STMW needed to be larger than the values of $K$ used for SAMW and SPMW, which were also on the larger side of previous estimates of $K$, because very little STMW is eroded via turbulent mixing.

\section{Conclusions}

[46] By combining models and observations using BMA, we can find volume transport spectra and mass fraction erosion spectra for three mode waters. These results give us information about subduction rates over time, residence times, and the timescales of erosion. SAMW is the mode water with the longest residence times. The North Atlantic mode waters erode by processes with at least two distinguishable timescales. Only about $20 \%$ of SAMW and STMW erode via entrainment back into the mixed layer and less than $5 \%$ of SPMW erodes this way. Turbulent mixing is likely to be responsible for over $70 \%$ of the erosion of SAMW, $50 \%$ of the erosion of SPMW, and $10 \%$ of the erosion of STMW. The remaining process responsible for the erosion of mode waters is presumably the air-sea flux that occurs. Air-sea flux, on average, makes a relatively small contribution to the erosion of SAMW compared to the erosion of the North Atlantic mode waters.

[47] Consistent with Liu and Huang [2012], our estimates provide some evidence that mode water subduction rates have increased in the North Atlantic and Southern Oceans over the last several decades, but none of these trends are significant at the $95 \%$ level. The long-term increasing trend in the SAM may be able to explain an increase in the entrainment/detrainment velocity-based SAMW subduction rates, but the interannual variability in the winter SAM index does not correlate well with that of our entrainment/ detrainment velocity-based subduction rate estimates. The interannual variability in the winter NAO index, on the other hand, correlates fairly well with that of our STMW entrainment/detrainment velocity-based subduction rate estimates. Diffusion is likely to account for about $20 \%$ of the subduction of SAMW. Diffusion is likely to account for about one-third of the subduction of STMW, but very little of the subduction of SPMW.

[48] Several of our formation rate estimates (6 $\mathrm{Sv}$ for STMW, 22-27 Sv for SPMW, and 27-46 Sv for SAMW) and subduction rate estimates (5.5-7.5 Sv for STMW, 1.53.5 Sv for SPMW, and 9.5-24 Sv for SAMW) are comparable with previous ones. For example, Trossman et al. [2009] estimated STMW (North Atlantic) subduction to be about 3-8 Sv from 2002 to 2005 with about 50\% error without accounting for mixing and Forget et al. [2011] estimated the annual formation rates of STMW due to airsea fluxes to be $2-11 \mathrm{~Sv}$ of flow sustained for a year. However, the formation rate estimates for SPMW and SAMW presented here are on the high side of previous formation rate estimates of SPMW (7.5-20.5 Sv from Brambilla et al. [2008]) and SAMW (23.6 Sv from Sloyan and Rintoul [2001]). This could be explained by our use of formulation developed by Speer and Tziperman [1992] rather than the formulation developed by Maze et al. [2009] to estimate formation rates. The relatively small detrainment rates of SPMW compared to SPMW formation rates provide evidence that the majority of SPMW in the North Atlantic forms by processes other than subduction, while the majority of STMW in the North Atlantic forms by way of subduction. In the Southern Ocean, the SAMW detrainment rates compared to SAMW formation rates suggest that the majority of SAMW formed by way of subduction before the 1990 s, but the majority of SAMW formed via processes other than subduction from the 1990s onward.

[49] Some caveats here are that our TTD-based estimates may not sufficiently capture the variability in subduction rates even within the range of our estimated uncertainties. Because HIM/Offtrac does not resolve eddies, it is possible that the eddy parameterizations are insufficient in HIM/ Offtrac and large residence times are not accounted for entirely. It is also possible that we have varied the circulation fields and $\kappa_{H}$ outside of the realistic domain, which could inflate the uncertainties if a similar effect on the final simulated CFC-11 concentrations could be achieved through varying another model parameter. For example, it could be that the diapycnal diffusivity according to its Hallberg [2000] parameterization could be erroneous in important ways. Finally, the low resolution of the model could result in circulation fields that have significant biases and the circulation 
fields may not have been varied enough to provide accurate subduction rate estimates.

[50] Further studies are needed to establish the possible link between the SAM and SAMW subduction, the possible link between the NAO and STMW and/or SPMW subduction, whether mode water subduction has been increasing over time, and whether along-isopycnal diffusion is a cause of the increase in mode water subduction over time. Lovenduski and Gruber [2005] found that a positive SAM leads to an increase in downwelling in SAMW formation regions which influences the transport and sequestration of carbon dioxide, which is consistent with our findings. Downes et al. [2009] predicted a decrease in transport of SAMW across $32^{\circ} \mathrm{S}$ under a future climate change scenario, but consistent with our entrainment/detrainment velocitybased estimates (because they used similar methods of estimation), little change (a slight decrease) in SAMW subduction was found. Further studies are needed to establish the extent to which an increasing subduction rate trend will persist since few previous studies have taken subductioncontributing diffusive processes into account. Lastly, further studies are needed to investigate the factors responsible for the changing relative contributions of various processes to the formation and erosion of mode waters such as SAMW.

\section{Appendix A: Mathematical Formalism of BMA}

[51] We have six different configurations of CFC-11 model simulations (three climatological runs and three hindcast runs) and our goal is to weight each of these model configurations by the relative degree to which we believe in them. A quantity of interest, $X$, (which can be any output variable or parameter of the model, but here are the mean residence times and formation/subduction/entrainment/ detrainment rates) has a probability density which no single model configuration can estimate. Each model configuration can only yield a precise estimate of $X$. To estimate the probability density of $X$, given the observations, (i.e., a posterior probability) we define the probability of the $j$ th model configuration being the true model for the data amongst all possible models, $M_{1}, \ldots, M_{6}$, which we denote by $m_{j}$. We let the CFC-11 concentration according to the $j$ th model simulation at a location and time be $D_{\text {model }, j}=D_{o b s}^{*}+\epsilon_{\text {model }, j}$, where $D_{o b s}^{*}=D_{o b s}+\epsilon_{o b s}$ is the observed CFC-11 concentration, $D_{o b s}$ is the actual CFC-11 concentration, $\epsilon_{o b s}$ is the error in the observed CFC-11 concentration from objectively mapped bottle data at a location and time (which we model with a Gaussian distribution), and $\epsilon_{\text {model, } j}$ is the error of the $j$ th model simulation relative to the observation at a location and time (which we model with a different Gaussian distribution from $\left.\epsilon_{o b s}\right)$. Then we calculate the posterior probability with

$$
m_{j}=P\left(M_{j} \mid D_{o b s}\right)=\frac{P\left(D_{o b s} \mid M_{j}\right) P\left(M_{j}\right)}{\sum_{i=1}^{k} P\left(D_{o b s} \mid M_{i}\right) P\left(M_{i}\right)} \propto P\left(D_{o b s} \mid M_{j}\right) P\left(M_{j}\right),
$$

where $\sum_{j=1}^{k} m_{j}=1$ and $P\left(M_{j}\right)$ is a prior belief, or first-guess distribution without incorporating information from the observations on the $j$ th model.
[52] To estimate each $P\left(D_{o b s} \mid M_{j}\right)$, we need to incorporate the uncertainty associated with the CFC-11 observations. Here, $D_{o b s}^{*}$ are sampled from a normal distribution, $N$ $\left(\mu_{o b s}, \epsilon_{o b s}^{2}\right)$, within the Markov Chain Monte Carlo, or MCMC, algorithm (e.g., explained in an oceanographic context by Goes et al. [2010]. The mean of the normal distribution, $\mu_{o b s}$, equals the objectively mapped value for CFC-11 concentration and the variance, $\epsilon_{o b s}^{2}$, equals $\left(0.02 \times D_{o b s}^{*}\right)^{2}+\left(\sigma_{\text {objm }}\right)^{2}$, where the measurement error is $0.02 \times D_{o b s}^{*}$ and error due to mapping the bottle data, estimated with a thin-plate spline [Trossman et al., 2011], is $\sigma_{\text {objm }}$. By incorporating the uncertainty associated with the CFC-11 observations, we find the likelihood to be given by

$$
\begin{aligned}
P\left(D_{o b s} \mid D_{o b s}^{*}, M_{j}\right)= & \prod_{x, t, s} \frac{1}{\sqrt{2 \pi\left(\sigma_{C F C-11, j}\right)^{2}}} \\
& \cdot \exp \left[-\frac{\left(D_{o b s}^{*(s(x, t))}-D_{\text {model }, j}^{(s(x, t))}\right)^{2}}{2\left(\sigma_{C F C-11, j}\right)^{2}}\right],
\end{aligned}
$$

of the $j$ th model output is interpreted to be the probability that the data (here, the observed CFC-11 concentrations, $D_{o b s}$, at the times, $t$, and locations, $x$, along sections, $s$, in which we have them) is perfectly simulated by the $j$ th model's output (here, its CFC-11 concentrations, $D_{\text {model, } j \text {, }}$ at the same times and locations), and the width of the likelihood,

$$
\sigma_{C F C-11, j}=\sqrt{\frac{1}{N-1} \sum_{x, t, s}\left(D_{o b s}^{*(s(x, t))}-D_{m o d e l, j}^{(s(x, t))}\right)^{2}} .
$$

The uncertainties associated with $D_{o b s}$ in the likelihood, (A2), for each model simulation are integrated out by performing MCMC to evaluate the integrated likelihood, given by

$$
P\left(D_{o b s} \mid M_{j}\right)=\int d D_{o b s}^{*} P\left(D_{o b s} \mid D_{o b s}^{*}, M_{j}\right) P\left(D_{o b s}^{*} \mid M_{j}\right)
$$

where $P\left(D_{o b s}^{*} \mid M_{j}\right)$ is a prior belief on the CFC-11 observations given the CFC-11 concentrations from the $j$ th model.

[53] Finally, we calculate $m_{j}$ by taking a large number of samples from $P\left(M_{j} \mid D_{o b s}\right)$ via MCMC that take on the value one (when $m_{j}$ is found to be a better model than the previous iteration) or zero (when not). The way we take a sample of $P\left(M_{j} \mid D_{o b s}\right)$ at each MCMC iteration is as follows: we let the $(n-1)$ th sample of the set (Markov Chain) of samples whose proportion of ones determines $P\left(M_{j} \mid D_{o b s}\right)$ be one for model, $M_{j}^{*}(n-1)$, and zero for all other models. Then letting the model, $M_{j}^{*}(n)$, be the proposed best model for the $n$th sample in the Markov Chain, we accept or reject $M_{j}^{*(n)}$ as the best model in the current iteration according to an acceptance probability,

$$
A\left(M_{j}^{*(n-1)}, M_{j}^{*(n)}\right)=\min \left\{1, \frac{P\left(M_{j}^{*(n)}\right) P\left(D_{o b s} \mid M_{j}^{*(n-1)}\right)}{P\left(M_{j}^{*(n-1)}\right) P\left(D_{o b s} \mid M_{j}^{*(n)}\right)}\right\} .
$$


Here, $A\left(M_{j}^{*}(n-1), M_{j}^{*(n)}\right)=A^{*}$ is compared with a random number, $x$, where $0 \leq x \leq 1$. We set the $n$th sample in the Markov Chain for model $M_{j}^{*(n)}$ equal to one if $A^{*} \geq x$ and the $n$th sample in the Markov Chain for model $M_{j}^{*}(\bar{n}-1)$ is one if $A^{*}<x$. The posterior probability, $m_{j}$, is set to be the proportion of ones for model $M_{j}$.

[54] Using the above posterior probabilities, $m_{j}$, equal to the proportion of the Markov Chain with value $j$ formed by performing $\mathrm{MCMC}$, we can find an estimate for the expected value and variance of this estimate for an output of our models. Specifically, our final model estimate of $X$ (which here represents the mean residence time or entrainment/ detrainment/subduction/formation rate) is given by

$$
\hat{X}=\sum_{j=1}^{k} m_{j} X_{j}
$$

where $X_{j}$ is the value of $X$ according to model $M_{j}$. Also, for $\operatorname{Var}\left[X \mid M_{j}, D_{o b s}\right]$ being the variance of the estimator of $X$ according to model $M_{j}$, the variance on our estimator of $X$ is given by

$$
\operatorname{Var}[\hat{X}]=\sum_{j=1}^{k} m_{j} \operatorname{Var}\left[X \mid M_{j}, D_{o b s}\right]
$$

where $\operatorname{Var}\left[X \mid M_{j}, D_{o b s}\right]$ is just the variance of the Markov Chain of ones and zeroes found with MCMC for the $j$ th model simulation multiplied by the square of the TTD- and entrainment/detrainment velocity-based estimates of subduction rates inferred from the simulation of model $j$. All MCMC runs here take 10,000 posterior samples of $P\left(M_{j} \mid D_{o b s}\right)$ in each basin to calculate the weights, $m_{j}$, equal to the mean value of the Markov Chain of values for $M_{j}(0$ or 1$)$. Because there is autocorrelation between the Markov Chains starting from the first and $b$ th sample for $b<b_{\text {in }}=1,000$ and because it may take several accept/reject iterations to find the posterior distribution, we only use sample numbers $b_{\text {in }}$ to 10,000 as posterior samples. This makes 9,000 samples for each location and depth. Throughout the main body of the text, we refer to $m_{j}(j=1, \ldots, 6)$ as the BMA weights.

[55] Acknowledgments. The authors are grateful for the helpful comments of two anonymous reviewers and the technical support provided by David Darr with running HIM. Thanks to Vladimir Minin and Peter Guttorp for their review of our methods and the providers of the CFC data we used in this study. This study was supported by NSF grants OCE-0525874 and OCE-0623548.

\section{References}

Abernathey, R., J. Marshall, M. Mazloff, and E. Shuckburgh (2010), Enhancement of mesoscale eddy stirring at steering levels in the Southern Ocean, J. Phys. Oceangr., 40, 170-184.

Brambilla, E., L. D. Talley, P. E. Robbins (2008), Subpolar Mode Water in the northeastern Atlantic: 2. Origin and transformation, J. Geophys. Res. 113, C04026, doi:10.1029/2006JC004063.

Carton, J. A., G. Chepurin, X. Gao, and B. S. Giese (2000), A simple ocean data assimilation analysis of the global upper ocean 1950-95. Part I: Methodology, J. Phys. Oceangr., 30, 294-309.

Deutsch, C., H. Brix, T. Ito, H. Frenzel, and L. Thompson (2011), Climate forcing of ocean hypoxia, Science, 333, 336-339, doi:10.1126/ science. 1202422 .

Doney, S. C., et al. (2004), Evaluating global ocean carbon models: The importance of realistic physics, Global Biogeochem. Cycles, 18, GB3017, doi:10.1029/2003GB002150.
Downes, S. M., N. L. Bindoff, and S. R. Rintoul (2009), Impacts of climate change on the subduction of Mode and Intermediate Water masses in the Southern Ocean, J. Clim., 22, 3289-3302.

Downes, S. M., A. G. Gnanadesikan, S. M. Griffies, and J. L. Sarmiento (2011), Water mass exchange in the Southern Ocean in coupled climate models, J. Phys. Oceangr., 41, 1756-1771.

Forget, G., G. Maze, M. Buckley, and J. Marshall (2011), Estimated seasonal cycle of North Atlantic Eighteen Degree Water volume, J. Phys. Oceangr., 41, 269-286.

Goes, M., N. M. Urban, R. Tonkonojenkov, M. Haran, A. Schmittner, and K. Keller (2010), What is the skill of ocean tracers in reducing uncertainties about ocean diapycnal mixing and projections of the Atlantic Meridional Overturning Circulation?, J. Geophys. Res., 115, C12006, doi:10.1029/2010JC006407.

Haine, T. W. N., H. Zhang, D. W. Waugh, and M. Holzer (2008), On transit-time distributions in unsteady circulation models, Ocean Modell. 21, 35-45.

Hall, T. M., T. W. N. Haine, M. Holzer, D. A. LeBel, F. Terenzi, and D. W. Waugh (2007), Ventilation rates estimated from tracers in the presence of mixing, J. Phys. Oceanogr., 37, 2599-2611.

Hallberg, R. (1995), Some aspects of the circulation in ocean basins with isopycnals intersecting the sloping boundaries, $\mathrm{PhD}$ thesis, $244 \mathrm{pp}$., Univ. of Wash., Seattle.

Hallberg, R. (2000), Time integration of diapycnal diffusion and Richardson number-dependent mixing in isopycnal coordinate ocean models, Mon. Weather Rev., 128, 1402-1419.

Hartin, C. A., R. A. Fine, B. M. Sloyan, L. D. Talley, T. K. Chereskin, and J. Happell (2011), Formation rates of subantarctic mode water and Antarctic intermediate water within the South Pacific, Deep Sea Res., Part I, 58(5), 524-534

Hoeting, J. A., D. Madigan, A. E. Raftery, and C. T. Volinsky (1999), Bayesian model averaging: A tutorial, Stat. Sci., 14(4), 382-417.

Holzer, M., and T. M. Hall (2000), Transit-time and tracer-age distributions in geophysical flows, J. Atmos. Sci., 57, 3539-3558.

Johnson, G. C., J. L. Bullister, and N. Gruber (2005), Labrador Sea Water property variations in the northeastern Atlantic Ocean, Geophys. Res. Lett., 32, L07602, doi:10.1029/2005GL022404.

Kunze, E., E. Firing, J. M. Hummon, T. K. Chereskin, and A. M. Thurnherr (2006), Global abyssal mixing inferred from lowered ADCP shear and CTD strain profiles, J. Phys. Oceanogr., 36(8), 1553-1576.

Kwon, Y.-O. (2003), Observation of general circulation and water mass variability in the North Atlantic Subtropical Mode Water region, PhD dissertation, Univ. of Wash., Seattle.

Kwon, Y.-O., and S. C. Riser (2004), North Atlantic Subtropical Mode Water: A history of ocean-atmosphere interaction 1961-2000, Geophys. Res. Lett., 31, L19307, doi:10.1029/2004GL021116.

Ladd, C., and L. Thompson (2001), Water mass formation in an isopycnal model of the North Pacific, J. Phys. Oceanogr., 31, 1517-1537.

Large, W. G., and S. G. Yeager (2004), Diurnal to decadal global forcing for ocean and sea-ice models: The datasets and flux climatologies, Tech. Note TN-460+STR, Natl. Cent. for Atmos. Res., Boulder, Colo.

LeBel, D. A., et al. (2008), The formation rate of North Atlantic Deep Water and Eighteen Degree Water calculated from CFC-11 inventories observed during WOCE, Deep Sea Res., Part I, 55, 891-910.

Liu, L. L., and R. X. Huang (2012), The global subduction/obduction rates: Their interannual and decadal variability, J. Clim., 25, 1096-1115.

Lovenduski, N. S., and N. Gruber (2005), Impact of the Southern Annular Mode on Southern Ocean circulation and biology, Geophys. Res. Lett., 32, L11603, doi:10.1029/2005GL022727.

Luyten, J., J. Pedlosky, and H. Stommel (1983), The ventilated thermocline, J. Phys. Oceanogr., 13, 292-309.

Maze, G., and J. Marshall (2011), Diagnosing the observed seasonal cycle of Atlantic Subtropical Mode Water using potential vorticity and its attendant theorems, J. Phys. Oceanogr., 41, 1986-1999.

McCartney, M. S. (1977), Subantarctic Mode Water, in A Voyage of Discovery: George Deacon 70th Anniversary Volume, edited by M. V. Angel, pp. 103-119, Pergamon, Oxford, U. K.

McCartney, M. S. (1982), The subtropical recirculation of Mode Waters, J. Mar. Res., 40, supplement, 427-464.

McCartney, M. S., and L. D. Talley (1982), The subpolar mode water of the North Atlantic Ocean, J. Phys. Oceanogr., 12, 1169-1188.

Maze, G., G. Forget, M. Buckley, J. Marshall, and I. Cerovecki (2009), Using transformation and formation maps to study the role of air-sea heat fluxes in North Atlantic Eighteen Degree Water formation, J. Phys. Oceanogr., 39, 1818-1835.

McDonagh, E. L., H. L. Bryden, B. A. King, R. J. Sanders, S. A. Cunningham, and R. Marsh (2005), Decadal changes in the South Indian Ocean thermocline, J. Clim., 18, 1575-1590. 
Mecking, S., M. J. Warner, C. E. Greene, S. L. Hautala, and R. E. Sonnerup (2004), Influence of mixing on CFC uptake and CFC ages in the North Pacific thermocline, J. Geophys. Res., 109, C07014, doi:10.1029/ 2003JC001988

Musgrave, D. L. (1990), Numerical studies of tritium and helium-3 in the thermocline, J. Phys. Oceanogr., 20, 344-373.

Percival, D. B., and A. T. Walden (2000), Wavelet Methods for Time Series Analysis, Cambridge Univ. Press, Cambridge, U. K.

Polzin, K., J. M. Toole, J. R. Ledwell, and R. W. Schmitt (1997), Spatial variability of turbulent mixing in the abyssal ocean, Science, 276(5309), 93-96.

Primeau, F. W., and M. Holzer (2006), The ocean's memory of the atmosphere: Residence-time distributions and water-mass ventilation, J. Phys. Oceanogr., 36, 1439-1456.

Read, J. F. (2001), CONVEX-91: Water masses and circulation of the northeast Atlantic subpolar gyre, Prog. Oceanogr., 48, 461-510.

Sallée, J.-B., N. Wienders, K. Speer, and R. Morrow (2006), Formation of Subantarctic Mode Water in the southeastern Indian Ocean, Ocean Dyn., 56, 525-542, doi:10.1007/s10236-005-0054-x.

Sallée, J. B., K. Speer, and S. R. Rintoul (2010), Zonally asymmetric response of the Southern Ocean mixed-layer depth to the Southern Annular Mode, Nat. Geosci., 3, 273-279.
Shuckburgh, E., G. Maze, D. Ferreira, J. Marshall, H. Jones, and C. Hill (2011), Mixed layer lateral eddy fluxes mediated by air-sea interaction, J. Phys. Oceanogr., 41, 130-144.

Sloyan, B. M. and S. R. Rintoul (2001), Circulation, renewal, and modification of Antarctic Mode and Intermediate Water, J. Phys. Oceanogr., 31, 1005-1030.

Sloyan, B. M., L. D. Talley, T. K. Chereskin, R. Fine, and J. Holte (2010), Antarctic Intermediate Water and Subantarctic Mode Water formation in the southeast Pacific: The role of turbulent mixing, J. Phys. Oceanogr., 40, 1558-1574.

Speer, K., and E. Tziperman (1992), Rates of water mass formation in the North Atlantic Ocean, J. Phys. Oceanogr., 22, 93-104.

Trossman, D. S., L. Thompson, K. A. Kelly, and Y.-O. Kwon (2009), Estimates of North Atlantic ventilation and mode water formation for winters 2002-06, J. Phys. Oceanogr., 39(10), 2600-2617.

Trossman, D. S., L. Thompson, and S. L. Hautala (2011), Application of thin-plate splines in two dimensions to oceanographic tracer data, J. Atmos. Oceanic Technol., 28(11), 1522-1538.

Waugh, D. W., T. M. Hall, and T. W. N. Haine (2003), Relationships among tracer ages, J. Geophys. Res., 108(C5), 3138, doi:10.1029/ 2002JC001325.

Worthington, L. (1959), The $18^{\circ}$ water in the Sargasso Sea, Deep Sea Res., $5,297-305$ 